\title{
B77 Impact Test Data Processing
}

\author{
R. E. Humphrey, E. D. Holbrook
}

\section{When printing a copy of any digitized SAND} Report, you are required to update the markings to current standards.

\section{Sandia Laboratories}


Issued by Sandia Laboratories, operated for the United States Department of Energy by Sandia Corporation.

\section{NOTICE}

This report was prepared as an account of work sponsored by the United States Government. Neither the United States nor the United States Department of Energy, nor any of their employees, nor any of their contractors, subcontractors, or their employees, makes any warranty, express or implied, or assumes any legal liability or responsibility for the accuracy, completeness or usefulness of any information, apparatus, product or process disclosed, or represents that its use would not infringe privately owned rights. 
SAND76-8027

Unlimited Release

Printed December 1977

B77 IMPACT TEST DATA PROCESSING

\author{
R. E. Humphrey \\ Advanced Mechanical Division 8158 \\ E. D. Holbrook \\ Data Processing Division 8411 \\ Sandia Laboratories
}

\begin{abstract}
With the system of equations presented, variables which describe the motion of B77 Impact Test Units can be obtained from high-speed motion picture data. Equations are developed that describe the kinematics of the body in terms of linear and angular positions, velocities and acceleration, flight path azimuth and elevation angles, and total angle of attack and windward meridian angle. The dynamics of the body are described in terms of its linear and angular momentum, its kinetic and potential energies, and the external forces and moments.
\end{abstract}




\section{TABLE OF CONTENTS}

Page

1. Introduction $\quad 11$

2. Coordinate Systems 11

3. Kinematics 13

$\begin{array}{lr}\text { 4. Dynamics } & 19\end{array}$

5. Data Processing Procedures 28

Appendix A--User's Instructions for Program IMPACT 35

Appendix B--Sample Data Plots 53 


\section{ILLUSTRATIONS}

Figure

Page

1. Inertial, Local Reference and Body-Fixed

12 Coordinate Systems

2. Trajectory Azimuth and Flight Path Angles 18

3. Total Angle of Attack and Windward 18 Meridian Angle

4. Center of Mass and $i^{\text {th }}$ Mass Particle 20 
TABLES

Table

$\underline{\text { Page }}$

I. Constants and Parameters

28

II. Input Variables

29

III. Output Variables

$30-32$ 


\title{
B77 IMPACT TEST DATA PROCESSING
}

\author{
1. Introduction
}

In the B77 impact test program, both instrumented and noninstrumented units (ITUs) are impacted on targets at various velocities and attitudes. During each test, the units are photographed by several high-speed motion picture cameras. The sequences of photographs obtained are processed using an image matching technique to obtain the position and attitude of the body at discrete times. From this data, the following variables that describe the motion of the body during impact can be obtained: velocity and acceleration of various points in the body, angular velocity and acceleration, linear and angular momentum, kinetic and potential energies, and external forces and moments. Other variables that describe the trajectory of the body, such as the trajectory azimuth and flight path angles, the total angle of attack, and the windward meridian angle, can also be obtained.

This report presents a derivation of a system of equations used to obtain the variables that describe the motion of the body from the measured values of position and attitude. Section 2 of this report defines the coordinate systems used in the analysis. Equations which describe the kinematics and the dynamics of the body are developed in Sections 3 and 4 respectively. Section 5 describes the data processing procedure which can be used to obtain the variables of interest. A digital computer program that performs the required numerical computations is included in Appendix A. Sample data plots are shown in Appendix B.

\section{Coordinate Systems}

The Cartesian coordinate systems used in this analysis are defined by triads of mutually orthogonal unit vectors $(\vec{i}, \vec{j}, \vec{k})$ that define the positive directions of the coordinate system axes. Since all coordinate systems are right-handed, the position and orientation of any coordinate system are uniquely specified by the location of the origin and the directions of any two of the vectors of the triad $(\vec{i}, \vec{j}, \vec{k})$. 
For this analysis, an Earth-fixed coordinate system is assumed as the inertial reference coordinate system. As shown in Figure 1, the origin of the inertial coordinate system $\left(\vec{i}_{i}, \vec{j}_{i}, \vec{k}_{i}\right)$ is located at the midpoint of a line segment between bench marks B. M. 1 and B. M. 2; the $\vec{k}_{i}$ axis coincides with the local vertical and is directed upward; and the $\overrightarrow{j_{i}}$ axis coincides with the line between B. M. 1 and B. M. 2 and is directed from B. M. 1 toward B. M. 2 .

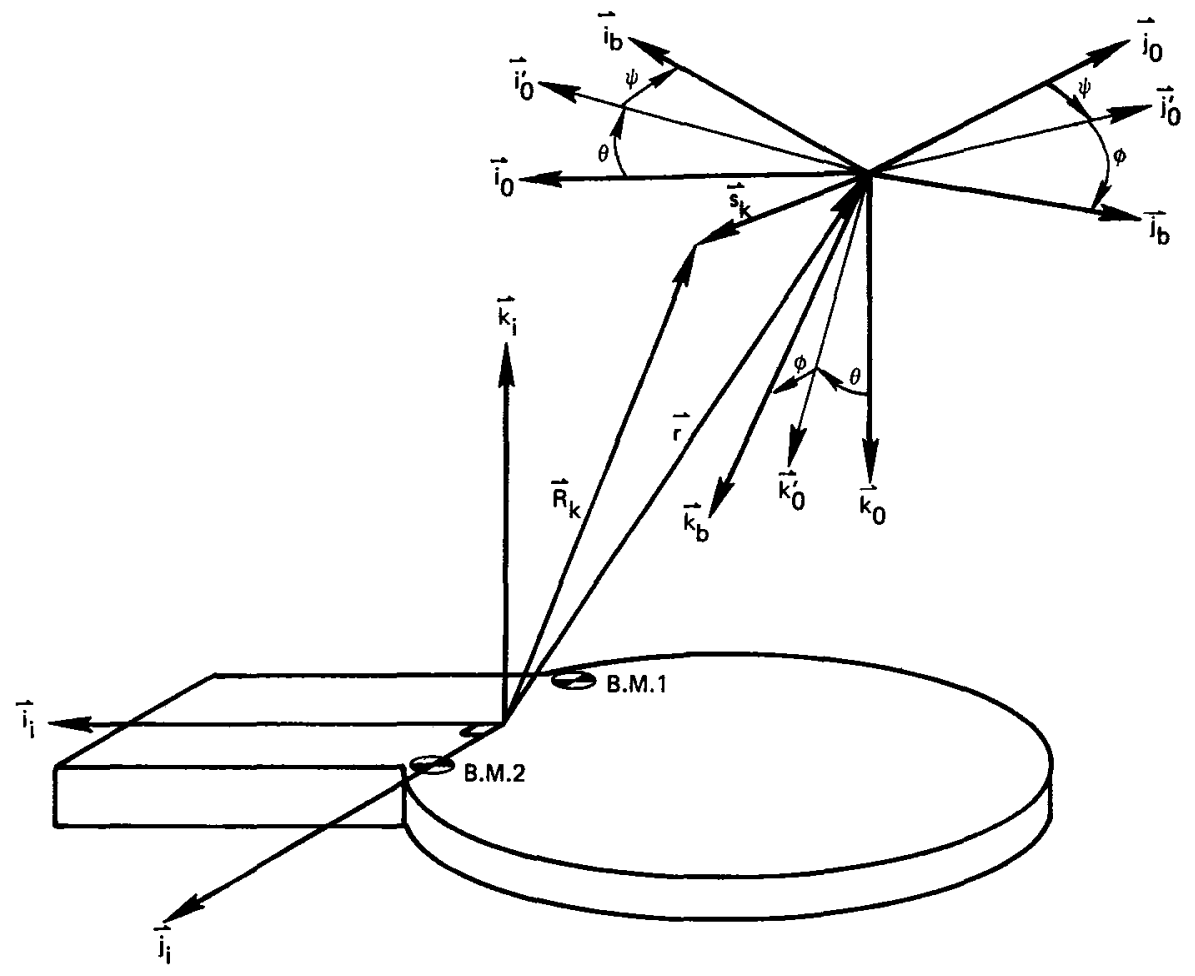

Figure 1. Inertial, Local Reference and Body-Fixed Coordinate Systems

The local reference coordinate system $\left(\vec{i}_{0}, \vec{j}_{0}, \vec{k}_{0}\right)$ is obtained from the inertial coordinate system by a translation so that the origin coincides with a point fixed in the body, followed by a positive rotation about the $\overrightarrow{\mathrm{i}}_{0}$ axis through an angle of $180^{\circ}$. The position of the point is described by the vector $\vec{r}$.

The body-fixed coordinate system $\left(\vec{i}_{b}, \vec{j}_{b}, \vec{k}_{b}\right)$ is obtained from the local reference coordinate system by an ordered sequence of three positive rotations, as illustrated in Figure 1. The first rotation is through an angle $\theta$ about $\vec{j}_{0}$ to obtain $\left(i_{0}^{\prime}, j_{0}, k_{0}^{\prime}\right)$; the second rotation is through an angle $\psi$ 
about $\overrightarrow{\mathrm{k}}_{0}^{\prime}$ to obtain $\left(\overrightarrow{\mathrm{i}}_{\mathrm{b}}, \overrightarrow{\mathrm{j}}_{0}^{\prime}, \overrightarrow{\mathrm{k}}_{0}^{\prime}\right)$; the third rotation is through an angle $\phi$ about $\vec{i}_{b}$ to obtain $\left(\vec{i}_{b}, \vec{j}_{b}, \vec{k}_{b}\right)$.

\section{Kinematics}

The vector $\vec{r}$, which describes the position of the origin of the bodyfixed coordinate system, can be expressed in terms of its components along the inertial coordinate system axes as

$$
\vec{r}=\vec{i}_{i} x+\vec{j}_{i} y+\vec{k}_{i} z
$$

The velocity of this point

$$
\vec{v}=\frac{d \vec{r}}{d t}
$$

can be expressed either in terms of its components along the inertial coordinate system axes as

$$
\vec{v}=\vec{i}_{i} \dot{x}+\vec{j}_{i} \dot{y}+\vec{k}_{i} \dot{z}
$$

where

$$
\begin{aligned}
& \dot{x}=\frac{d x}{d t} \\
& \dot{y}=\frac{d y}{d t} \\
& \dot{z}=\frac{d z}{d t}
\end{aligned}
$$

or in terms of its components along the body-fixed coordinate system axes as

$$
\vec{v}=\vec{i}_{b} u+\vec{j}_{b} v+\vec{k}_{b} w
$$

These two sets of components are related by

$$
\left(\begin{array}{l}
u \\
v \\
W
\end{array}\right)=A(\theta, \psi, \phi) B(\pi)\left(\begin{array}{l}
\dot{x} \\
\dot{y} \\
\dot{z}
\end{array}\right)
$$


where $A(\theta, \psi, \phi)$ is a matrix defined by

$\mathrm{A}(\theta, \psi, \phi)=\mathrm{B}(\phi) \mathrm{C}(\psi) \mathrm{D}(\theta)$

$$
\begin{aligned}
& \mathrm{B}(\phi)=\left[\begin{array}{ccc}
1 & 0 & 0 \\
0 & \cos \phi & \sin \phi \\
0 & -\sin \phi & \cos \phi
\end{array}\right] \\
& \mathrm{C}(\psi)=\left[\begin{array}{ccc}
\cos \psi & \sin \psi & 0 \\
-\sin \psi & \cos \psi & 0 \\
0 & 0 & 1
\end{array}\right] \\
& \mathrm{D}(\theta)=\left[\begin{array}{ccc}
\cos \theta & 0 & -\sin \theta \\
0 & 1 & 0 \\
\sin \theta & 0 & \cos \theta
\end{array}\right]
\end{aligned}
$$

Let

$$
\vec{\omega}=\vec{i}_{b} p+\vec{j}_{b} q+\vec{k}_{b} r
$$

represent the angular velocity of the body expressed in terms of its components along the body-fixed coordinate system axes. The components $\mathrm{p}$, $q$, and $r$ are related to the time rates of change of the Euler angles

$$
\left(\begin{array}{l}
\dot{\theta} \\
\dot{\psi} \\
\dot{\phi}
\end{array}\right)=\left(\begin{array}{l}
\frac{\mathrm{d} \theta}{\mathrm{dt}} \\
\frac{\mathrm{d} \psi}{\mathrm{dt}} \\
\frac{\mathrm{d} \phi}{\mathrm{dt}}
\end{array}\right)
$$

by

$$
\left(\begin{array}{l}
p \\
q \\
r
\end{array}\right)=Q(\psi, \phi)\left(\begin{array}{l}
\dot{\theta} \\
\dot{\psi} \\
\dot{\phi}
\end{array}\right)
$$


where

$$
\mathrm{Q}(\psi, \phi)=\left[\begin{array}{ccc}
\sin \psi & 0 & 1 \\
\cos \phi \cos \psi & \sin \phi & 0 \\
-\sin \phi \cos \psi & \cos \phi & 0
\end{array}\right]
$$

Let

$$
\overrightarrow{\mathrm{R}}_{\mathrm{k}}=\overrightarrow{\mathrm{r}}+\overrightarrow{\mathbf{s}}_{\mathrm{k}}
$$

represent the position of the $\mathrm{k}^{\text {th }}$ arbitrarily chosen point which is fixed in the body. The velocity of this point is then

$$
\begin{aligned}
\vec{V}_{k} & =\frac{d \vec{R}_{k}}{d t} \\
& =\vec{v}+\frac{\delta \vec{s}_{k}}{\delta t}+\vec{\omega} \times \vec{s}_{k}
\end{aligned}
$$

where $\frac{\delta \vec{s}_{k}}{\delta t}$ represents the velocity of the point as seen in the body-fixed coordinate system. Since, by hypothesis, the point is fixed in the body,

$$
\frac{\delta \vec{s}_{\mathrm{k}}}{\delta \mathrm{t}}=0
$$

and Equation (3.16) becomes

$$
\overrightarrow{\mathrm{V}}_{\mathrm{k}}=\overrightarrow{\mathrm{v}}+\vec{w} \times \overrightarrow{\mathrm{s}}_{\mathrm{k}}
$$

This vector can be expressed in terms of its components along the bodyfixed coordinate system axes as

$$
\vec{V}_{k}=\vec{i}_{b} U_{k}+\vec{j}_{b} V_{k}+\vec{k}_{b} W_{k}
$$

where

$$
\left(\begin{array}{c}
U_{k} \\
v_{k} \\
W_{k}
\end{array}\right)=\left(\begin{array}{l}
u \\
v \\
w
\end{array}\right)+\left(\begin{array}{l}
{ }^{q} s_{k z}-r s_{k y} \\
r s_{k x}-p s_{k z} \\
p s_{k y}-q s_{k x}
\end{array}\right)
$$


and $s_{k x}, s_{k y}$, and $s_{k z}$ are the components of $\vec{s}_{k}$ in the body-fixed coordinate system, i. e.,

$$
\vec{s}_{k}=\vec{i}_{b} s_{k x}+\vec{j}_{b} s_{k y}+\vec{k}_{b} s_{k z}
$$

The acceleration of $\vec{R}_{k}$ is given by

$$
\begin{aligned}
\vec{A}_{k} & =\frac{d \vec{V}_{k}}{d t} \\
& =\frac{d}{d t}\left(\vec{v}+\vec{\omega} \times \vec{s}_{k}\right) \\
& =\vec{a}+\vec{\omega} \times\left(\frac{\delta \vec{s}_{k}}{\delta t}+\vec{\omega} \times \vec{s}_{k}\right)+\left(\frac{\delta \vec{\omega}}{\delta t}+\vec{\omega} \times \vec{\omega}\right) \times \vec{s}_{k} \\
& =\vec{a}+\vec{\omega} \times\left(\vec{\omega} \times \vec{s}_{k}\right)+\vec{b} \times \vec{s}_{k}
\end{aligned}
$$

where

$$
\vec{a}=\frac{d \vec{v}}{d t}
$$

is the acceleration of the origin of the body-fixed coordinate system, and where

$$
\overrightarrow{\mathrm{b}}=\frac{\delta \vec{\omega}}{\delta \mathrm{t}}
$$

is the angular acceleration of the body.

The linear acceleration can be expressed either in terms of its components along the inertial or body-fixed coordinate system axes as

$$
\begin{aligned}
\vec{a} & =\vec{i}_{i} \ddot{x}+\vec{j}_{i} \ddot{y}+\vec{k}_{i} \ddot{z} \\
& =\vec{i}_{b} \dot{u}+\vec{j}_{b} \dot{v}+\vec{k}_{b} \dot{w}
\end{aligned}
$$

where 


$$
\begin{aligned}
& \left(\begin{array}{l}
\ddot{x} \\
\ddot{y} \\
\ddot{z}
\end{array}\right)=\left(\begin{array}{l}
\frac{d \dot{x}}{d t} \\
\frac{d \dot{y}}{d t} \\
\frac{d \dot{z}}{d t}
\end{array}\right) \\
& \left(\begin{array}{l}
\dot{u} \\
\dot{v} \\
\dot{w}
\end{array}\right)=A(\theta, \psi, \phi) B(\pi)\left(\begin{array}{c}
\ddot{x} \\
\ddot{y} \\
\ddot{z}
\end{array}\right)
\end{aligned}
$$

The angular acceleration can be expressed in terms of its components along the body-fixed coordinate system axes as

$$
\overrightarrow{\mathrm{b}}=\overrightarrow{\mathrm{i}_{\mathrm{b}}} \dot{\mathrm{p}}+\overrightarrow{\mathrm{j}}_{\mathrm{b}} \dot{\mathrm{q}}+\overrightarrow{\mathrm{k}}_{\mathrm{b}} \dot{\mathrm{s}}
$$

where

$$
\left(\begin{array}{l}
\dot{p} \\
\dot{q} \\
\dot{r}
\end{array}\right)=\left(\begin{array}{l}
\frac{d p}{d t} \\
\frac{d q}{d t} \\
\frac{d r}{d t}
\end{array}\right)
$$

With these results, $\vec{A}_{k}$ can be expressed in terms of its components along the body-fixed coordinate system axes as

$$
\vec{A}_{k}=\vec{i}_{b} A_{k x}+\vec{j}_{b} A_{k y}+\vec{k}_{b} A_{k z}
$$

where

$$
\left(\begin{array}{c}
A_{k x} \\
A_{k y} \\
A_{k z}
\end{array}\right)=\left(\begin{array}{c}
\dot{u} \\
\dot{v} \\
\dot{w}
\end{array}\right)+\left(\begin{array}{l}
p\left(q s_{k y}+r s_{k z}\right)-\left(q^{2}+r^{2}\right) s_{k x} \\
q\left(r s_{k z}+p s_{k x}\right)-\left(r^{2}+p^{2}\right) s_{k y} \\
r\left(p s_{k x}+q s_{k y}\right)-\left(p^{2}+q^{2}\right) s_{k z}
\end{array}\right)+\left(\begin{array}{l}
\dot{q} s_{k z}-\dot{r} s_{k y} \\
\dot{r} s_{k x}-\dot{p} s_{k z} \\
\dot{p} s_{k x}
\end{array}\right)
$$

With reference now to Figure 2, the azimuth angle $\zeta$ is the angle between the projection of the velocity vector $\vec{v}$ on the $\left(\vec{i}_{i}, \vec{j}_{i}\right)$ plane and the axis defined by $\vec{i}_{i}$. The flight path angle $\beta$ is the angle between the velocity vector and its projection on the $\left(\overrightarrow{i_{i}}, \overrightarrow{j_{i}}\right)$ plane. These angles are given by 


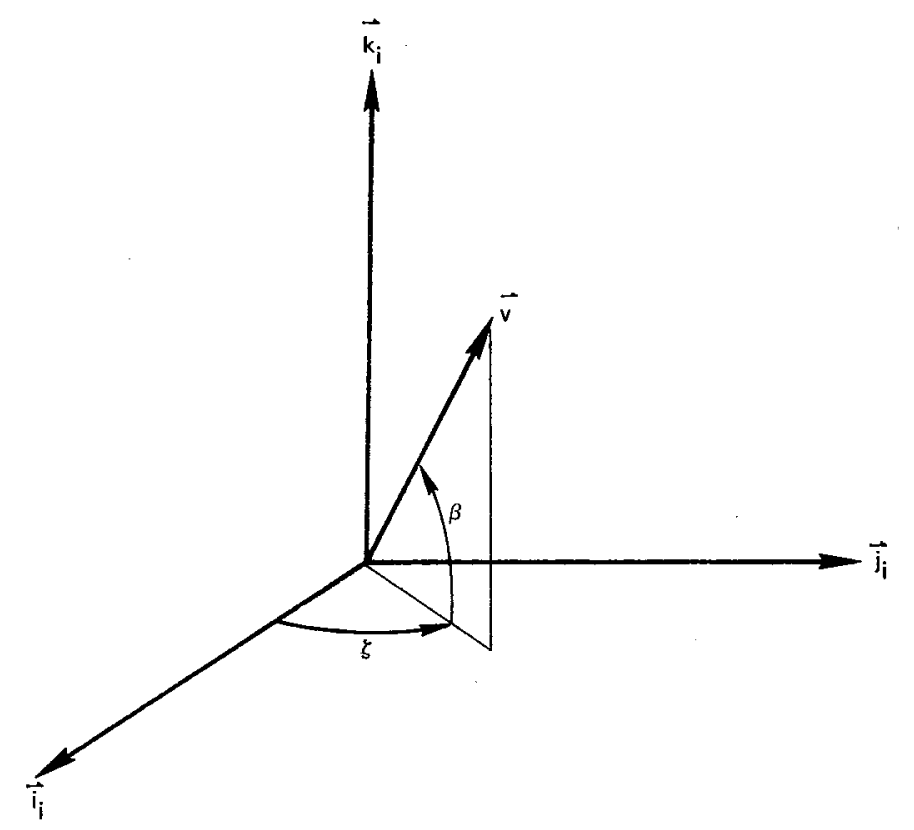

Figure 2. Trajectory Azimuth and Flight Path Angles

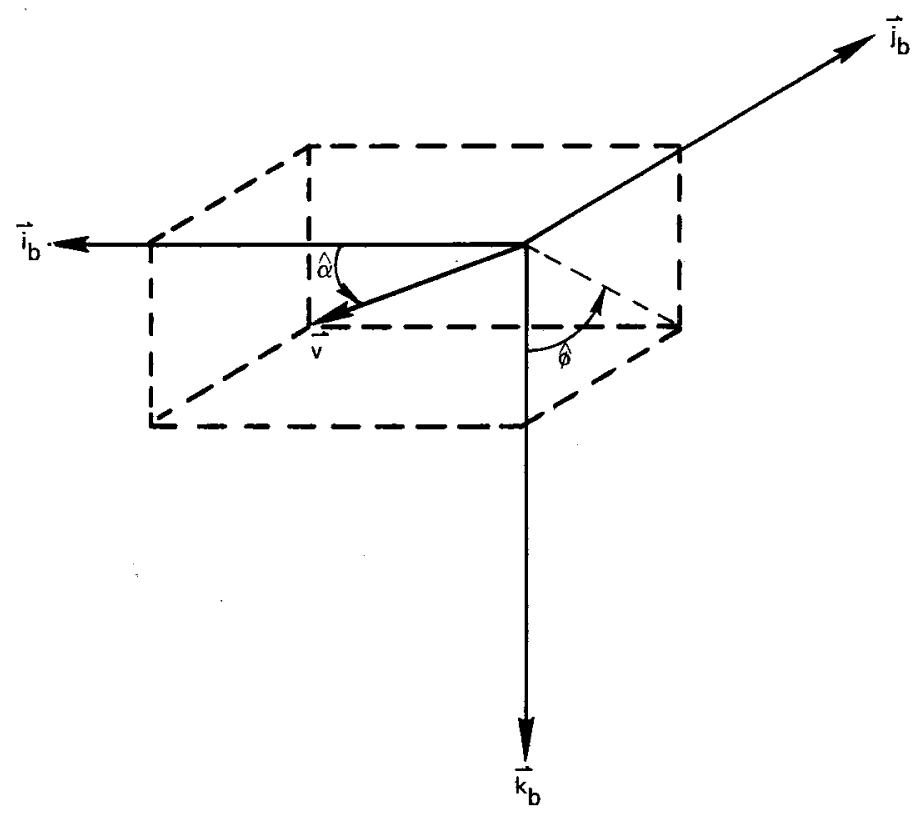

Figure 3. Total Angle of Attack and Windward Meridian Angle 


$$
\begin{aligned}
& \zeta=\operatorname{atan}\left(\frac{\dot{\mathrm{y}}}{\dot{\mathrm{x}}}\right) \\
& \beta=\operatorname{atan} \frac{\dot{\mathrm{z}}}{\sqrt{\dot{\mathrm{x}}^{2}+\dot{\mathrm{y}}^{2}}}
\end{aligned}
$$

As illustrated in Figure 3, the total angle of attack $\hat{\alpha}$ is the angle between the velocity vector $\vec{v}$ and $\vec{i}_{b}$. The windward meridian angle $\hat{\phi}$ is the angle between projection of $\vec{v}$ on the $\left(\vec{j}_{b}, \vec{k}_{b}\right)$ plane and $\vec{k}_{b}$. These angles are given by

$$
\begin{aligned}
& \hat{\alpha}=\operatorname{atan}\left(\frac{\sqrt{\mathrm{u}^{2}+\mathrm{w}^{2}}}{\mathrm{u}}\right) \\
& \hat{\phi}=\operatorname{atan}\left(\frac{\mathrm{V}}{\mathrm{w}}\right)
\end{aligned}
$$

The magnitude of the velocity of the origin of the body-fixed coordinate system is given by

$$
\begin{aligned}
\nu & =\sqrt{u^{2}+v^{2}+w^{2}} \\
& =\sqrt{\dot{x}^{2}+\dot{y}^{2}+\dot{z}^{2}}
\end{aligned}
$$

The magnitude of the velocity of the $k^{\text {th }}$ point fixed in the body is given by

$$
\nu_{k}=\sqrt{\mathrm{U}_{\mathrm{k}}^{2}+\mathrm{v}_{\mathrm{k}}^{2}+\mathrm{w}_{\mathrm{k}}^{2}}
$$

\section{Dynamics}

With reference to Figure 4 , let $m_{i}$ represent the mass of the $i^{\text {th }}$ infinitesimal mass particle of the body and let its position be described by the vector

$$
\vec{r}_{i}=\vec{r}+\vec{\rho}_{i}
$$




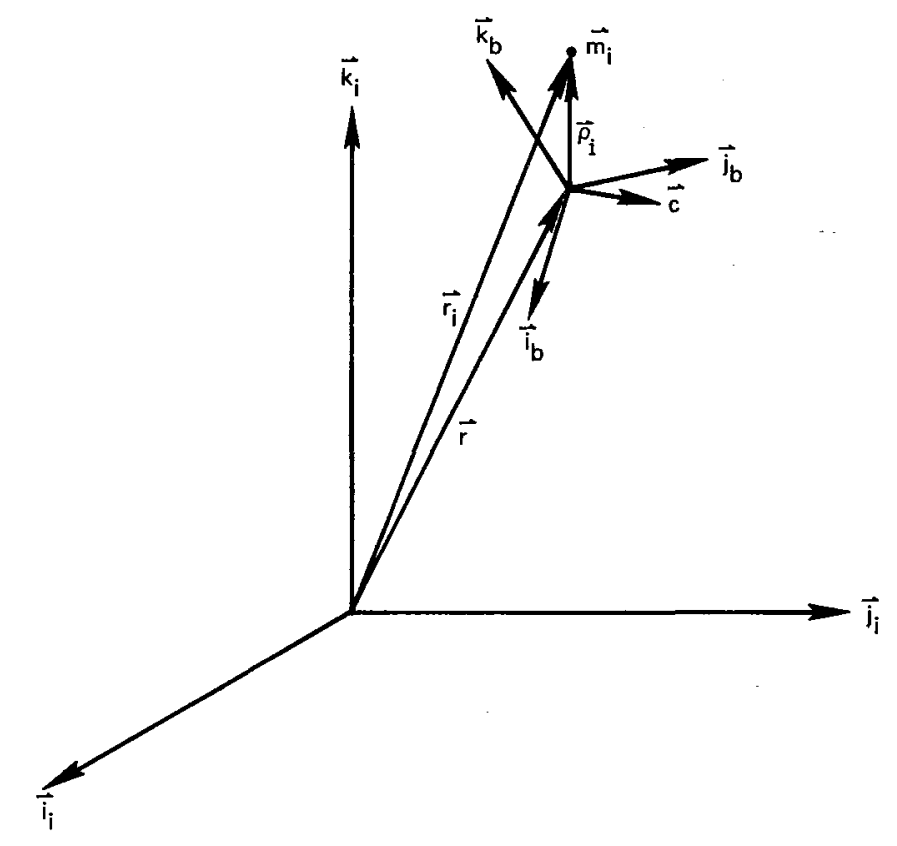

Figure 4. Center of Mass and $i^{\text {th }}$ Mass Particle 
The kinetic energy associated with the body is the sum of the kinetic energies of the individual mass particles and is given by

$$
T=\frac{1}{2} \sum_{i} m_{i} \frac{d \vec{r}_{i}}{d t} \cdot \frac{d \vec{r}_{i}}{d t}
$$

The velocity of the $i^{\text {th }}$ mass particle is given by

$$
\frac{d \vec{r}_{i}}{d t}=\vec{v}+\frac{\delta \vec{\rho}_{i}}{\delta t}+\vec{\omega} \times \vec{\rho}_{\mathbf{i}}
$$

where $\frac{\delta \rho_{i}}{\delta t}$ represents the velocity of the $i^{\text {th }}$ mass particle as seen in the body-fixed coordinate system. If the body is assumed to be rigid,

$$
\frac{\overrightarrow{\delta \rho_{i}}}{\delta t}=0
$$

and consequently

$$
\frac{d \vec{r}_{i}}{d t}=\vec{v}+\vec{\omega} \times \vec{\rho}_{i}
$$

With this result, Equation (4.2) can be written as

$$
\begin{aligned}
& T=\frac{1}{2} \sum_{i} m_{i}\left(\vec{v}+\vec{\omega} \times \overrightarrow{\rho_{i}}\right) \cdot\left(\vec{v}+\vec{\omega} \times \vec{\rho}_{i}\right) \\
& =\frac{1}{2} \sum_{i} m_{i} \vec{v} \cdot \vec{v}+\sum_{i} m_{i} \vec{v} \cdot\left(\vec{\omega} \times \overrightarrow{\rho_{i}}\right)+\frac{1}{2} \sum_{i} m_{i}\left(\vec{\omega} \times \overrightarrow{\rho_{i}}\right) \cdot\left(\vec{\omega} \times \overrightarrow{\rho_{i}}\right) \\
& =\frac{1}{2} \overrightarrow{\mathrm{m}} \overrightarrow{\mathrm{v}} \cdot \overrightarrow{\mathrm{v}}+\overrightarrow{\mathrm{v}} \cdot(\vec{\omega} \times \overrightarrow{\mathrm{m}} \overrightarrow{\mathrm{c}})+\frac{1}{2} \vec{\omega} \cdot \sum_{\mathbf{i}}\left(\vec{\rho}_{\mathrm{i}} \times \mathrm{m}_{\mathrm{i}}\left(\vec{\omega} \times \vec{\rho}_{\mathrm{i}}\right)\right) \\
& =\frac{1}{2} \overrightarrow{\mathrm{m}} \vec{v} \cdot \vec{v}+\vec{v} \cdot(\vec{\omega} \times \overline{\mathrm{m}} \overrightarrow{\mathrm{c}})+\frac{1}{2} \vec{\omega} \cdot \overrightarrow{\overrightarrow{\mathrm{I}}} \vec{\omega}
\end{aligned}
$$

where $\overrightarrow{\mathrm{I}}$ represents the inertia tensor defined by

$$
\overrightarrow{\vec{I}} \vec{\omega}=\sum_{i}\left(\vec{\rho}_{i} \times m_{i}\left(\vec{\omega} \times \vec{\rho}_{i}\right)\right)
$$


The total mass of the body is represented by

$$
\overline{\mathrm{m}}=\sum_{\mathbf{i}} \mathrm{m}_{\mathrm{i}}
$$

and the center of mass of the body in the body-fixed coordinate system is represented by

$$
\overrightarrow{\mathrm{c}}=\frac{\sum_{\mathrm{i}} \mathrm{m}_{\mathrm{i}} \vec{\rho}_{\mathrm{i}}}{\overline{\mathrm{m}}}
$$

Equation (4.6) can be written in the form

$$
T=\frac{1}{2} \vec{v} \cdot(\overline{\mathrm{m}} \overrightarrow{\mathrm{v}}+\vec{\omega} \times \overline{\mathrm{m}} \overrightarrow{\mathrm{c}})+\frac{1}{2} \vec{\omega} \cdot \overrightarrow{\mathrm{I}} \vec{\omega}+\frac{1}{2} \vec{v} \cdot(\vec{\omega} \times \overline{\mathrm{m}} \overrightarrow{\mathrm{c}})
$$

Since

$$
\vec{v} \cdot(\vec{\omega} \times \bar{m} \vec{c})=\vec{\omega} \cdot(\bar{m} \vec{c} \times \vec{v})
$$

it follows that

$$
\begin{aligned}
T & =\frac{1}{2} \vec{v} \cdot(\bar{m} \vec{v}+\vec{\omega} \times \bar{m} \vec{c})+\frac{1}{2} \vec{\omega} \cdot(\overrightarrow{\vec{I}} \vec{\omega}+\bar{m} \vec{c} \times \vec{v}) \\
& =\frac{1}{2} \vec{v} \cdot \vec{G}+\frac{1}{2} \vec{\omega} \cdot \vec{H}
\end{aligned}
$$

where

$$
\vec{G}=\bar{m}(\vec{v}+\vec{\omega} \times \vec{c})
$$

represents the linear momentum of the body and

$$
\overrightarrow{\mathrm{H}}=\overrightarrow{\vec{I}} \vec{\omega}+\overrightarrow{\mathrm{m}} \overrightarrow{\mathrm{c}} \times \vec{v}
$$

represents the angular momentum about the origin of the body-fixed coordinate system.

With reference now to Equation (4.7), the components of the vector $\vec{I} \vec{\omega}$ can be conveniently expressed in terms of its components along the body-fixed coordinate system axes in the following manner. Let 


$$
\vec{\rho}_{i}=\vec{i}_{b} x_{i}+\vec{j}_{b} y_{i}+\vec{k}_{b} z_{i}
$$

be the representation of $\vec{\rho}_{i}$ in the body-fixed coordinate system. Then

$$
\begin{aligned}
\vec{I} \vec{\omega} & =\sum_{i} \vec{\rho}_{i} \times m_{i}\left(\vec{\omega} \times \vec{\rho}_{i}\right) \\
& =\vec{i}_{b}\left(I_{x x} p+I_{x y} q+I_{x z} r\right) \\
& +\vec{j}_{b}\left(I_{y x} p+I_{y y} q+I_{y z} r\right) \\
& +\vec{k}_{b}\left(I_{z x} p+I_{z y} q+I_{z z} r\right)
\end{aligned}
$$

where

$$
\begin{aligned}
& I_{x x}=\sum_{i} m_{i}\left(y_{i}^{2}+z_{i}^{2}\right) \\
& I_{y y}=\sum_{i} m_{i}\left(x_{i}^{2}+z_{i}^{2}\right) \\
& I_{z z}=\sum_{i} m_{i}\left(x_{i}^{2}+y_{i}^{2}\right) \\
& I_{x y}=I_{y x}=-\sum_{i} m_{i} x_{i} y_{i} \\
& I_{y z}=I_{z y}=-\sum_{i} m_{i} y_{i} z_{i} \\
& I_{z x}=I_{x z}=-\sum m_{i} z_{i} x_{i}
\end{aligned}
$$

are the moments and products of inertia in the body-fixed coordinate system.

With these results, the linear momentum can be expressed in terms of its components along the body-fixed coordinate system axes as

$$
\vec{G}=\vec{i}_{b} g_{x}+\vec{j}_{b} g_{y}+\vec{k}_{b} g_{z}
$$

where 


$$
\left(\begin{array}{l}
g_{x} \\
g_{y} \\
g_{z}
\end{array}\right)=\left[\begin{array}{ccc}
0 & \bar{m} c_{z} & -\bar{m} c_{y} \\
-\bar{m} c_{z} & 0 & \bar{m} c_{x} \\
\bar{m} c_{y} & -\bar{m} c_{x} & 0
\end{array}\right]\left(\begin{array}{l}
p \\
q \\
r
\end{array}\right)+\left[\begin{array}{ccc}
\bar{m} & 0 & 0 \\
0 & \bar{m} & 0 \\
0 & 0 & \bar{m}
\end{array}\right]\left(\begin{array}{l}
u \\
v \\
w
\end{array}\right)
$$

The angular momentum can also be expressed in terms of its components along the body-fixed coordinate system axes as

$$
\vec{H}=\vec{i}_{b} h_{x}+\vec{j}_{b} h_{y}+\vec{k}_{b} h_{z}
$$

where

$$
\left(\begin{array}{c}
h_{x} \\
h_{y} \\
h_{z}
\end{array}\right)=\left[\begin{array}{ccc}
I_{x x} & I_{x y} & I_{x z} \\
I_{y x} & I_{y y} & I_{y z} \\
I_{z x} & I_{z y} & I_{z z}
\end{array}\right]\left(\begin{array}{l}
p \\
q \\
r
\end{array}\right)+\left[\begin{array}{ccc}
0 & -\bar{m} c_{z} & \bar{m} c y \\
\bar{m} c_{z} & 0 & -\bar{m} c \\
-\bar{m} c_{y} & \bar{m} c_{x} & 0
\end{array}\right]\left(\begin{array}{l}
u \\
v \\
w
\end{array}\right)
$$

Equation (4.12) can now be written as

$$
T=\frac{1}{2}\left(\begin{array}{l}
p \\
q \\
r \\
u \\
v \\
w
\end{array}\right)^{\prime}\left[\begin{array}{cccccc}
I_{x x} & I_{x y} & I_{x z} & 0 & -\bar{m} c_{z} & \bar{m} c y \\
I_{y x} & I_{y y} & I_{y z} & \bar{m} c_{z} & 0 & -\bar{m} c_{x} \\
I_{z x} & I_{z y} & I_{z z} & -\bar{m} c_{y} & \bar{m} c_{x} & 0 \\
0 & \bar{m} c_{z} & -\bar{m} c_{y} & \bar{m} & 0 & 0 \\
-\bar{m} c_{z} & 0 & \bar{m} c_{x} & 0 & \bar{m} & 0 \\
\bar{m} c_{y} & -\bar{m} c_{x} & 0 & 0 & 0 & \bar{m}
\end{array}\right]\left(\begin{array}{c}
p \\
q \\
r \\
u \\
v \\
w
\end{array}\right)
$$

The potential energy of the body is the sum of the potential energies of the individual mass properties. The potential energy due to gravity is

$$
\begin{aligned}
V & =\sum_{n} m_{n} \vec{r}_{n} \cdot \vec{k}_{i} g \\
& =\vec{k}_{i} g \cdot \sum_{n} m_{n}\left(\vec{r}+\vec{\rho}_{n}\right) \\
& =\bar{m}_{g} \vec{k}_{i} \cdot(\vec{r}+\vec{c})
\end{aligned}
$$


where $g$ represents the acceleration of gravity, which is assumed to be constant.

The vector $\vec{c}$ can be expressed in terms of its components along the inertial coordinate system axes as

$$
\vec{c}=\vec{i}_{i} c_{1}+\vec{j}_{i} c_{2}+\vec{k}_{i} c_{3}
$$

where

$$
\left(\begin{array}{l}
c_{1} \\
c_{2} \\
c_{3}
\end{array}\right)=[A(\theta, \psi, \phi) B(\pi)]^{-1}\left(\begin{array}{c}
c_{x} \\
c_{y} \\
c_{z}
\end{array}\right)
$$

Since $\mathrm{A}(\theta, \psi, \phi)$ and $\mathrm{B}(\phi)$ are orthonormal matrices, Equation $(4.30)$ can be written as

$$
\left(\begin{array}{l}
c_{1} \\
c_{2} \\
c_{3}
\end{array}\right)=B^{\prime}(\pi) A^{\prime}(\theta, \psi, \phi)\left(\begin{array}{c}
c_{x} \\
c_{y} \\
c_{z}
\end{array}\right)
$$

where $A^{\prime}$ and $B^{\prime}$ denote the transposes of $A$ and $B$ respectively. Equation $(4.28)$ can now be written as

$$
\begin{aligned}
V & =\bar{m} g \vec{k}_{i} \cdot(\vec{r}+\vec{c}) \\
& =\bar{m} g \vec{k}_{i} \cdot\left[\vec{i}_{i}\left(x+c_{1}\right)+\vec{j}_{i}\left(y+c_{2}\right)+\vec{k}_{i}\left(z+c_{3}\right)\right] \\
& =\bar{m} g\left(z+c_{3}\right)
\end{aligned}
$$

The total energy associated with the body is the sum of the potential and kinetic energies.

$$
E=T+V
$$


The external force and moment acting on the body are given by

$$
\begin{aligned}
\overrightarrow{\mathrm{F}} & =\frac{\mathrm{d} \overrightarrow{\mathrm{G}}}{\mathrm{dt}} \\
& =\frac{\mathrm{d}}{\mathrm{dt}}[\overline{\mathrm{m}}(\overrightarrow{\mathrm{v}}+\vec{\omega} \times \overrightarrow{\mathrm{c}})] \\
& =\overline{\mathrm{m}}\left[\overrightarrow{\mathrm{a}}+\vec{\omega} \times\left(\frac{\delta \overrightarrow{\mathrm{c}}}{\delta \mathrm{t}}+\vec{\omega} \times \overrightarrow{\mathrm{c}}\right)+\left(\frac{\delta \vec{\omega}}{\delta \mathrm{t}}+\vec{\omega} \times \vec{\omega}\right) \times \overrightarrow{\mathrm{c}}\right] \\
& =\overline{\mathrm{m}}\left[\overrightarrow{\mathrm{a}}+\vec{\omega} \times(\vec{\omega} \times \overrightarrow{\mathrm{c}})+\frac{\delta \vec{\omega}}{\delta \mathrm{t}} \times \overrightarrow{\mathrm{c}}\right]
\end{aligned}
$$

and

$$
\begin{aligned}
\overrightarrow{\mathrm{M}} & =\frac{\mathrm{d} \overrightarrow{\mathrm{H}}}{\mathrm{dt}}-(\vec{\omega} \times \overrightarrow{\mathrm{c}}) \times \mathrm{m} \overrightarrow{\mathrm{v}} \\
& \left.=\frac{\mathrm{d}}{\mathrm{dt}} \overrightarrow{\vec{I}} \vec{\omega}+\overrightarrow{\mathrm{m}} \overrightarrow{\mathrm{c}} \times \overrightarrow{\mathrm{v}}\right] \\
& =\overrightarrow{\vec{I}}\left(\frac{\delta \vec{\omega}}{\delta \mathrm{t}}+\vec{\omega} \times \vec{\omega}\right)+\overline{\mathrm{m}}\left[\overrightarrow{\mathrm{c}} \times \overrightarrow{\mathrm{a}}+\left(\frac{\delta \overrightarrow{\mathrm{c}}}{\delta \mathrm{t}}+\vec{\omega} \times \overrightarrow{\mathrm{c}}\right) \times \overrightarrow{\mathrm{v}}\right] \\
& =\overrightarrow{\overrightarrow{\mathrm{I}}} \frac{\delta \vec{\omega}}{\delta \mathrm{t}}+\overline{\mathrm{m}}[\overrightarrow{\mathrm{c}} \times \overrightarrow{\mathrm{a}}]
\end{aligned}
$$

The force and moment can be expressed either in terms of their components along the body-fixed or the inertial coordinate system axes as

$$
\begin{aligned}
\vec{F} & =\vec{i}_{b} X+\vec{j}_{b} Y+\vec{k}_{b} z \\
& =\vec{i}_{i} f x+\vec{j}_{i} f+\vec{k}_{i} f z
\end{aligned}
$$

and

$$
\begin{aligned}
\vec{M} & =\vec{i}_{b} L+\vec{j}_{b} M+\vec{k}_{b} N \\
& =\vec{i}_{i} l+\vec{j}_{i} m+\vec{k}_{i} n
\end{aligned}
$$

where

$$
\left(\begin{array}{l}
X \\
Y \\
z
\end{array}\right)=\bar{m}\left(\begin{array}{l}
\dot{u} \\
\dot{v} \\
\dot{w}
\end{array}\right)+\left(\begin{array}{l}
p\left(q c_{y}+r c_{z}\right)-\left(q^{2}+r^{2}\right) c_{x} \\
q\left(r c_{z}+p c_{x}\right)-\left(r^{2}+p^{2}\right) c_{y} \\
r\left(p c_{x}+q c_{y}\right)-\left(p^{2}+q^{2}\right) c_{z}
\end{array}\right)+\left(\begin{array}{l}
\dot{q} c_{z}-\dot{r} c_{y} \\
\dot{r} c_{x}-\dot{p} c_{z} \\
\dot{p} c_{y}-\dot{q} c_{x}
\end{array}\right)
$$




$$
\left(\begin{array}{l}
f_{x} \\
f \\
y \\
f \\
z
\end{array}\right)=B^{\prime}(\pi) A^{\prime}(\theta, \psi, \phi)\left(\begin{array}{l}
x \\
y \\
z
\end{array}\right)
$$

and

$$
\left.\left(\begin{array}{l}
L \\
M \\
N
\end{array}\right)=\left[\begin{array}{ccc}
I_{x x} & I_{x y} & I_{x z} \\
I_{y x} & I & I \\
y y & I_{y z} \\
I_{z x} & I_{z y} & I_{z z}
\end{array}\right]\left(\begin{array}{l}
p \\
q
\end{array}\right)+\bar{m}\left[\begin{array}{c}
\dot{\dot{w}} c y^{-}-\dot{v} c_{z} \\
\dot{u} c_{z}-\dot{w} c_{x} \\
\dot{v} c_{x}-\dot{u} c_{y}
\end{array}\right)+\left(\begin{array}{l}
w\left(r c_{x}-p c_{z}\right)-v\left(p c_{y}-q c_{x}\right) \\
u\left(p c_{y}-q c_{x}\right)-w\left(q c_{z}-r c_{y}\right) \\
v\left(q c_{z}-r c_{y}\right)-u\left(r c_{x}-p c_{z}\right)
\end{array}\right]\right)
$$

$$
\left(\begin{array}{l}
\ell \\
m \\
n
\end{array}\right)=B^{\prime}(\pi) A^{\prime}(\theta, \psi, \phi)\left(\begin{array}{l}
\mathrm{L} \\
M \\
N
\end{array}\right)
$$

With reference now to Equations $(4.23)$ through $(4.26)$, the linear and angular momentum vectors can be expressed in terms of their components in the inertial coordinate system as

$$
\vec{G}=\vec{i}_{i} G_{x}+\vec{j}_{i} G_{y}+\vec{k}_{i} G_{z}
$$

and

$$
\vec{H}=\vec{i}_{i} H_{x}+\vec{j}_{i} H_{y}+\vec{k}_{i} H_{z}
$$

respectively where

$$
\left(\begin{array}{l}
G_{x} \\
G_{y} \\
G_{z}
\end{array}\right)=B^{\prime}(\pi) A^{\prime}(\theta, \psi, \phi)\left(\begin{array}{l}
g_{x} \\
g_{y} \\
g_{z}
\end{array}\right)
$$

and

$$
\left(\begin{array}{c}
H_{x} \\
H_{y} \\
H_{z}
\end{array}\right)=B^{\prime}(\pi) A^{\prime}(\theta, \psi, \phi)\left(\begin{array}{l}
h_{x} \\
h_{y} \\
h_{z}
\end{array}\right)
$$




\section{Data Processing Procedures}

The procedures that use the previously derived equations to process the impact test data are described in this section. The constants and parameters needed to process the data are listed in Table I. All constants, parameters, and variables must be in a consistent system of units. The English system of units with mass in slugs, length in feet, and time in seconds is specified to be consistent with existing capabilities. The parameters which describe the inertial properties of the body, the mass and the moments and products of inertia, are assumed to be piece-wise constant functions of time.

TABLE I

CONSTANTS AND PARAMETERS

\begin{tabular}{|c|c|c|}
\hline Symbol & Units & Remarks \\
\hline $\begin{array}{l}\mathrm{s}_{\mathrm{kx}} \\
\mathrm{s}_{\mathrm{ky}} \\
\mathrm{s}_{\mathrm{kz}}\end{array}$ & $\begin{array}{l}\mathrm{ft} \\
\mathrm{ft} \\
\mathrm{ft}\end{array}$ & $\begin{array}{l}\mathrm{k}=1,2, \ldots, \mathrm{K} \\
\text { Location of } \mathrm{kth} \text { point in the body at which } \\
\text { velocity and acceleration are to be computed. }\end{array}$ \\
\hline $\begin{array}{l}c_{x} \\
c_{y} \\
c_{z}\end{array}$ & $\begin{array}{l}\mathrm{ft} \\
\mathrm{ft} \\
\mathrm{ft}\end{array}$ & $\begin{array}{l}\text { Location of the center of mass (piece-wise } \\
\text { constant functions of time) }\end{array}$ \\
\hline$\overline{\mathrm{m}}$ & slugs & $\begin{array}{l}\text { Mass of the body (piece-wise constant } \\
\text { function of time) }\end{array}$ \\
\hline $\begin{array}{l}I_{x x} \\
I_{y y} \\
I_{y z} \\
I_{x y}=I_{y x} \\
I_{y z}=I_{z y} \\
I_{z x}=I_{x z}\end{array}$ & $\begin{array}{l}\text { slug-ft } \\
\text { slug-ft } \\
\end{array}$ & $\begin{array}{l}\text { Moments and products of inertia (piece- } \\
\text { wise constant functions of time) }\end{array}$ \\
\hline $\mathrm{g}$ & $\mathrm{ft} / \mathrm{sec}^{2}$ & Acceleration of gravity \\
\hline
\end{tabular}


The input variables are listed in Table II and the output variables in Table III. The input data consists of the three variables $x, y$, and $z$ that describe the position of one point fixed in the body (the origin of the bodyfixed coordinate system) and the three variables $\theta, \psi$, and $\phi$ that describe the angular position of the body. The values of these variables are obtained at discrete instants of time from photographs taken by high-speed motion picture cameras.

TABLE II

INPUT VARIABLES

\begin{tabular}{|c|c|c|}
\hline Symbol & Units & Remarks \\
\hline $\mathbf{x}$ & feet & \\
\hline $\mathrm{y}$ & feet & $\begin{array}{l}\text { Location of the origin of the body-fixed } \\
\text { coordinate system. }\end{array}$ \\
\hline $\mathbf{z}$ & feet & \\
\hline$\psi$ & radians * & \\
\hline$\theta$ & radians $*$ & $\begin{array}{l}\text { Euler angles which describe angular } \\
\text { position of the body }\end{array}$ \\
\hline$\phi$ & radians ${ }^{*}$ & . \\
\hline
\end{tabular}

*The computer program described in Appendix A uses angles measured in degrees rather than radians. 
TABLE III

OUTPUT VARIABLES

\begin{tabular}{|c|c|c|}
\hline Symbol & Units: & Remarks \\
\hline $\begin{array}{l}\dot{\mathrm{x}} \\
\dot{\mathrm{y}} \\
\dot{\mathrm{z}}\end{array}$ & $\begin{array}{l}\mathrm{ft} / \mathrm{sec} \\
\mathrm{ft} / \mathrm{sec} \\
\mathrm{ft} / \mathrm{sec}\end{array}$ & Inertial components of body velocity \\
\hline $\begin{array}{l}\dot{\psi} \\
\dot{\theta} \\
\dot{\phi}\end{array}$ & $\begin{array}{l}\text { radians/sec* } \\
\text { radians/sec* } \\
\text { radians/sec* }\end{array}$ & Time rate of change of Euler angles \\
\hline $\begin{array}{l}\mathrm{u} \\
\mathrm{v} \\
\mathrm{w}\end{array}$ & $\begin{array}{l}\text { radians/sec* } \\
\text { radians/sec* } \\
\text { radians/sec* }\end{array}$ & Body components of body velocity \\
\hline $\begin{array}{l}\mathrm{p} \\
\mathrm{q} \\
\mathrm{r}\end{array}$ & $\begin{array}{l}\text { radians / sec* } \\
\text { radians/sec* } \\
\text { radians/sec* }\end{array}$ & Body components of angular velocity \\
\hline $\begin{array}{c}\mathrm{U}_{\mathrm{k}} \\
\mathrm{v} \\
\mathrm{k} \\
\mathrm{k}\end{array}$ & $\begin{array}{l}\mathrm{ft} / \mathrm{sec} \\
\mathrm{ft} / \mathrm{sec} \\
\mathrm{ft} / \mathrm{sec}\end{array}$ & $\begin{array}{l}\text { Body components of velocity of } \mathrm{k}^{\text {th }} \text { point } \\
\text { fixed in the body }\end{array}$ \\
\hline $\begin{array}{l}\ddot{x} \\
\ddot{y} \\
\ddot{z}\end{array}$ & $\begin{array}{l}\mathrm{ft} / \mathrm{sec}^{2} \\
\mathrm{ft} / \mathrm{sec}^{2} \\
\mathrm{ft} / \mathrm{sec}^{2}\end{array}$ & Inertial components of acceleration \\
\hline $\begin{array}{l}\dot{\mathrm{p}} \\
\dot{\mathrm{q}} \\
\dot{\mathrm{r}}\end{array}$ & $\begin{array}{l}\mathrm{rad} / \mathrm{sec}^{2} * \\
\mathrm{rad} / \mathrm{sec}^{2} * \\
\mathrm{rad} / \mathrm{sec}^{2} *\end{array}$ & Body components of angular acceleration \\
\hline $\begin{array}{l}\dot{\mathrm{u}} \\
\dot{\mathrm{v}} \\
\dot{\mathrm{w}}\end{array}$ & $\begin{array}{l}\mathrm{ft} / \mathrm{sec}^{2} \\
\mathrm{ft} / \mathrm{sec}^{2} \\
\mathrm{ft} / \mathrm{sec}^{2}\end{array}$ & Body components of acceleration \\
\hline
\end{tabular}

*The computer program described in Appendix A uses angles measured in degrees rather than radians. 
TABLE III (continued)

\begin{tabular}{|c|c|c|}
\hline Symbol & Units & Remarks \\
\hline $\begin{array}{l}\mathrm{A}_{\mathrm{kx}} \\
\mathrm{A}_{\mathrm{ky}} \\
\mathrm{A}_{\mathrm{kz}}\end{array}$ & $\begin{array}{l}\mathrm{ft} / \mathrm{sec}^{2} \\
\mathrm{ft} / \mathrm{sec}^{2} \\
\mathrm{ft} / \mathrm{sec}^{2}\end{array}$ & $\begin{array}{l}\text { Body components of acceleration of } \mathrm{k}^{\text {th }} \\
\text { point fixed in the body }\end{array}$ \\
\hline $\begin{array}{l}\zeta \\
\beta \\
\hat{\alpha} \\
\hat{\phi} \\
\nu \\
\nu_{\mathrm{k}}\end{array}$ & $\begin{array}{l}\text { radians* } \\
\text { radians* } \\
\text { radians* } \\
\text { radians* } \\
\mathrm{ft} / \mathrm{sec} \\
\mathrm{ft} / \mathrm{sec}\end{array}$ & $\begin{array}{l}\text { Azimuth angle } \\
\text { Flight path angle } \\
\text { Total angle of attack } \\
\text { Windward meridian angle } \\
\text { Magnitude of velocity } \overrightarrow{\mathrm{v}} \\
\text { Magnitude of velocity } \overrightarrow{\mathrm{V}}_{\mathrm{k}}\end{array}$ \\
\hline $\begin{array}{l}g_{x} \\
g_{y} \\
g_{z}\end{array}$ & $\begin{array}{l}\text { slug-ft/sec } \\
\text { slug-ft/sec } \\
\text { slug-ft/sec }\end{array}$ & Body components of linear momentum \\
\hline $\begin{array}{l}h_{x} \\
h_{y} \\
h \\
z\end{array}$ & $\begin{array}{l}\text { slug-ft/sec } \\
\text { slug-ft/sec } \\
\text { slug-ft/sec }\end{array}$ & Body components of angular momentum \\
\hline $\begin{array}{l}\mathrm{T} \\
\mathrm{V} \\
\mathrm{E}\end{array}$ & $\begin{array}{l}\mathrm{ft}-1 \mathrm{bs} \\
\mathrm{ft}-1 \mathrm{bs} \\
\mathrm{ft}-\mathrm{lbs}\end{array}$ & $\begin{array}{l}\text { Kinetic energy of body } \\
\text { Potential energy of body } \\
\text { Total energy of body }\end{array}$ \\
\hline $\begin{array}{l}X \\
Y \\
Z\end{array}$ & $\begin{array}{l}\text { lbs } \\
\mathrm{lbs} \\
\mathrm{lbs}\end{array}$ & Body components of external force \\
\hline $\begin{array}{l}f_{x} \\
f_{y} \\
f_{z}\end{array}$ & $\begin{array}{l}1 \mathrm{bs} \\
1 \mathrm{bs} \\
\mathrm{lbs}\end{array}$ & Inertial components of external force \\
\hline
\end{tabular}

*The computer program described in Appendix A uses angles measured in degrees rather than radians. 
TABLE III (continued)

\begin{tabular}{|c|c|c|}
\hline Symbol & Units & Remarks \\
\hline $\begin{array}{l}\mathrm{L} \\
\mathrm{M} \\
\mathrm{N}\end{array}$ & $\begin{array}{l}f t-1 b s \\
f t-1 b s \\
f t-1 b s\end{array}$ & $\begin{array}{l}\text { Body components of external moment } \\
\text { about the origin of the body-fixed co- } \\
\text { ordinate system }\end{array}$ \\
\hline $\begin{array}{l}\ell \\
\mathrm{m} \\
\mathrm{n}\end{array}$ & $\begin{array}{l}f t-1 b s \\
f t-1 b s \\
f t-l b s\end{array}$ & $\begin{array}{l}\text { Inertial components of external moment } \\
\text { about the origin of the body-fixed co- } \\
\text { ordinate system }\end{array}$ \\
\hline $\begin{array}{l}G_{x} \\
G_{y} \\
G_{z}\end{array}$ & $\begin{array}{l}\text { slug-ft/sec } \\
\text { slug-ft/sec } \\
\text { slug-ft/sec }\end{array}$ & $\begin{array}{l}\text { Inertial components of linear } \\
\text { momentum }\end{array}$ \\
\hline $\begin{array}{l}\mathrm{H}_{\mathrm{x}} \\
\mathrm{H}_{\mathrm{y}} \\
\mathrm{H}_{\mathrm{z}}\end{array}$ & $\begin{array}{l}\text { slug-ft/sec } \\
\text { slug-ft/sec } \\
\text { slug-ft/sec }\end{array}$ & $\begin{array}{l}\text { Inertial components of angular } \\
\text { momentum }\end{array}$ \\
\hline
\end{tabular}


The variables $\dot{x}, \dot{y}, \dot{z}, \dot{\theta}, \dot{\psi}, \dot{\phi}$ defined by Equations (3.4) and (3.12) can be obtained by numerical differentiation techniques. The se techniques require input data over relatively large intervals of time to compute the derivatives at any one instant of time. Consequently, these six variables must be computed in a preliminary pass of the data.

Once the six derivatives mentioned above have been obtained, the elements of the matrix $\mathrm{A}(\theta, \psi, \phi)$ as defined by Equations (3. 7) through (3.10) can be computed, and the variables $u, v$, and $w$ can be computed from Equation (3.6). Similarly, the elements of the matrix $E(\psi, \phi)$ as defined by Equation (3.14) can be computed and the variables $p, q$, and $r$ obtained from Equation (3.13). The values of the variables $U_{k}, V_{k^{\prime}}$ and $W_{k}$ $(\mathrm{k}=1,2, \ldots, \mathrm{K})$ can be computed from Equation (3.20).

A second pass at the data is required to obtain the derivatives $\ddot{x}, \ddot{y}$, $\ddot{z}, \dot{p}, \dot{q}$, and $\dot{r}$ as defined by Equations (3.26 and (3.29). The values of the variables $\dot{\mathrm{u}}, \dot{\mathrm{v}}$, and $\dot{\mathrm{w}}$ can then be obtained from Equation (3.27), and the values of the variables $A_{k x}, A_{k y}$, and $A_{k z}(k=1,2, \ldots, K)$ can be obtained from Equation (3.31). The variables $\zeta, \beta, \hat{\alpha}, \hat{\phi}, \nu$, and $\nu_{\mathrm{k}}(\mathrm{k}=1,2, \ldots, \mathrm{K})$ can be obtained from Equations $(3.32)$ through $(3.37)$ respectively.

Next, the components of linear momentum $\left(g_{x}, g_{y}\right.$, and $\left.g_{z}\right)$ and the components of angular momentum $\left(\mathrm{h}_{\mathrm{x}}, \mathrm{h}_{\mathrm{y}}\right.$, and $\left.\mathrm{h}_{\mathrm{z}}\right)$ can be obtained from Equations (4.24) and (4.26) respectively. The kinetic energy $T$ can be obtained from Equation (4.27). The value of $c_{3}$ can be obtained from Equation (4.31), and the potential energy $\mathrm{V}$ can then be computed from Equation (4.32). The total energy is obtained from Equation (4.32). The components of external force in the body-fixed coordinate system $\mathrm{X}, \mathrm{Y}$, and $Z$ and in the inertial system $f_{x}, f_{y}$, and $f_{z}$ can be obtained from

Equations (4.38) and (4.39). Similarly, the components of the external moment in the two coordinate systems $L, M$, and $N$ and $\ell, m$, and $n$ can be obtained from Equations (4.40) and (4.41). 
APPENDIX A--USER'S INSTRUCTIONS FOR PROGRAM IMPACT

Introduction

The purpose of program IMPACT is to compute angular velocities and accelerations, linear velocities and accelerations of various points on a body, linear and angular momentum, kinetic and potential energies, and the external forces and moments from data obtained from high-speed photographic film of an impacting body. The equations used are described in the main text of this document. The program IMPACT exists on a permanent file named MACHLIB which is a part of Division 8411's Secondary Processing Library for the CDC 6600 computer. The program uses the word-addressable Master Disc File which is standard to all programs in the Secondary Processing Library.

File Structure

Master Disc File

The Master Disc File is a word-addressable file as described in the CDC 6000 Computer Systems User's Guide for Cyber Record Manager.

Word-Addressable File - General--The word-addressable file is one of several file formats available in the Record Manager System used by FORTRAN extended. The word-addressable file can be considered as one continuous string of data starting at word 1 at the beginning of the file and ending at word $N$, the last word in the file (see Figure A-1). Every word is uniquely identified by a number from 1 to N. The word-addressable files can be accessed randomly or sequentially and can only exist on mass storage. The user must do all of the bookkeeping to read or write data. 


\begin{tabular}{|c|}
\hline WORD 1 \\
\hline WORD 2 \\
\hline WORD 3 \\
\hline 1 \\
1 \\
1 \\
1 \\
1 \\
1 \\
1 \\
1 \\
1 \\
\hline WORD N-1 \\
WORD N \\
\hline
\end{tabular}

Figure A-1. Word-Addressable File

The word-addressable files used by the Data Reduction programs are specified record type $U$. This means that the records are not defined, and the user must specify a record length on both read and write operations. The Record Manager System cannot determine where the U type record begins or ends on a file. There are no ENDFILE indicators written on the files and they would be ignored if written.

The logical file names are defined in the program and are not listed in the program statement. With a few exceptions, the input file is named $\mathrm{MDF}$ and the output file MDF1. If any external file is attached, the user must be sure that the file has been renamed to conform with the logical file name internal to the program. This is done by using a FILE card and a LDSET card.

$$
\begin{aligned}
& \text { FILE ( } \ell \text { fn old, LFN = lfn new) } \\
& \text { LDSET (FILES }=\text { lfn old) }
\end{aligned}
$$

Word-Addressable File - Data Reduction- -The following is a brief description of the word-addressable file (WAF) used by the Data Reduction Secondary Processing Libraries. The structure maintains the original formal of the Master Disc File (MDF) with modifications necessary to make the file word-addressable. 
The first 900 words are reserved for the word address table that is maintained by the user for read and write operations. The first data entry is at address 901 and is always the IDT record for the first data channel. An $\mathrm{DT}$ record is entered for each channel of data in a frame or (data node) for the subfile. The IDT records must be written out in the same sequence as the sequence of the data in the data frame.

Following the IDT records are the data. The first word of the data record is a key word (DTA) followed by a second word which normally indicates the number of words in the record. (For the word-addressable file, the second word is not used.) The data follows the se two words in one continuous string to the end.

A terminator record (referred to as an END record) is written at the end of the data which consists of three words, END, 1, 0. This constitutes a subfile, and the number of subfiles that can be written is dependent upon the space available in the word address table.

If the WAF is written with one channel of data per subfile, 149 channels of data may be written. This means that there is room for only 149 unique identifiers in the word address table. However, if the WAF is written with 16 channels per frame, a maximum of 384 channels of data can be written out; these are located in a total of only 24 subfiles. Figure A-2 illustrates the file structure.

The IDT Record

The IDT record is a 128-word record which identifies a single channel of information in the MDF. The record also has the necessary parameters and labeling information to generate a plot of that data without reading in additional parameter cards. The description of the IDT record follows.

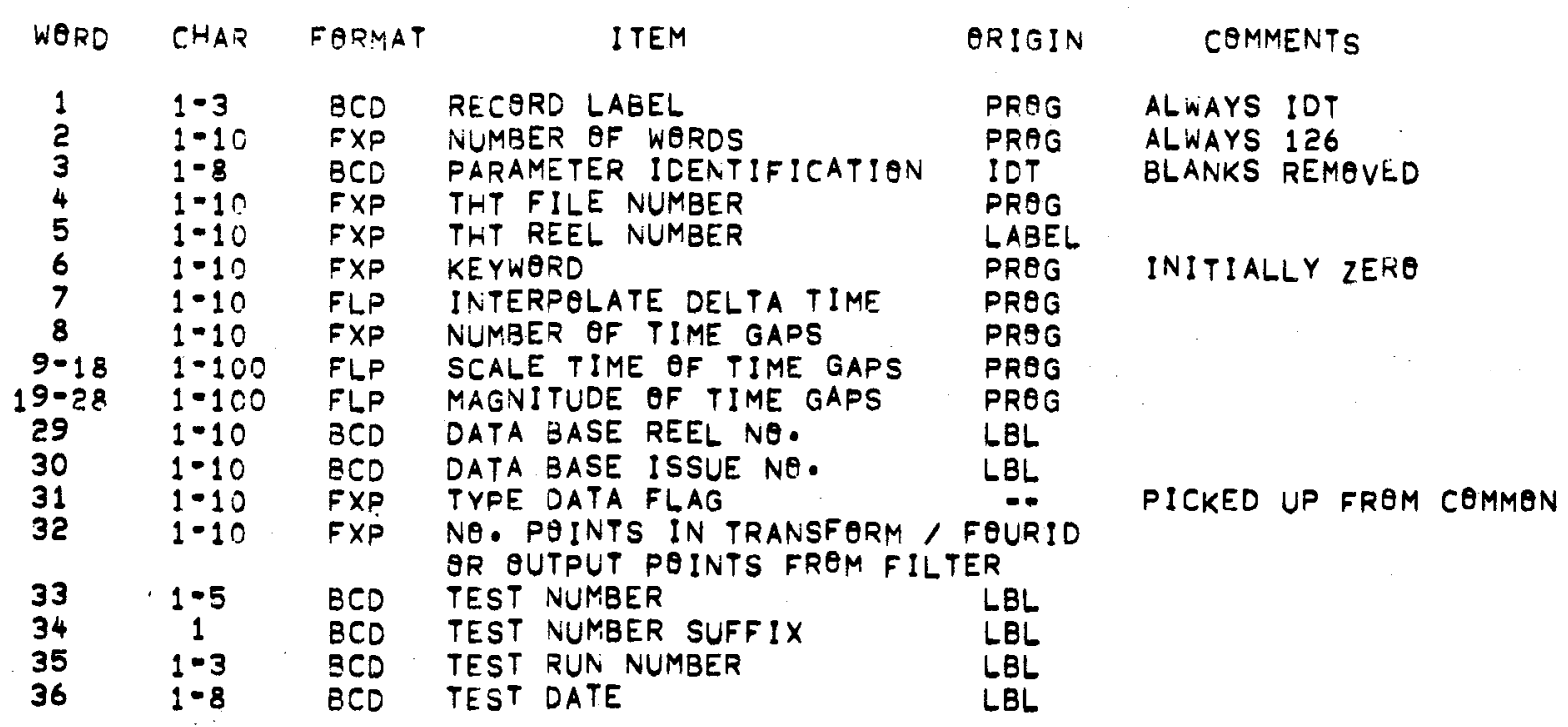




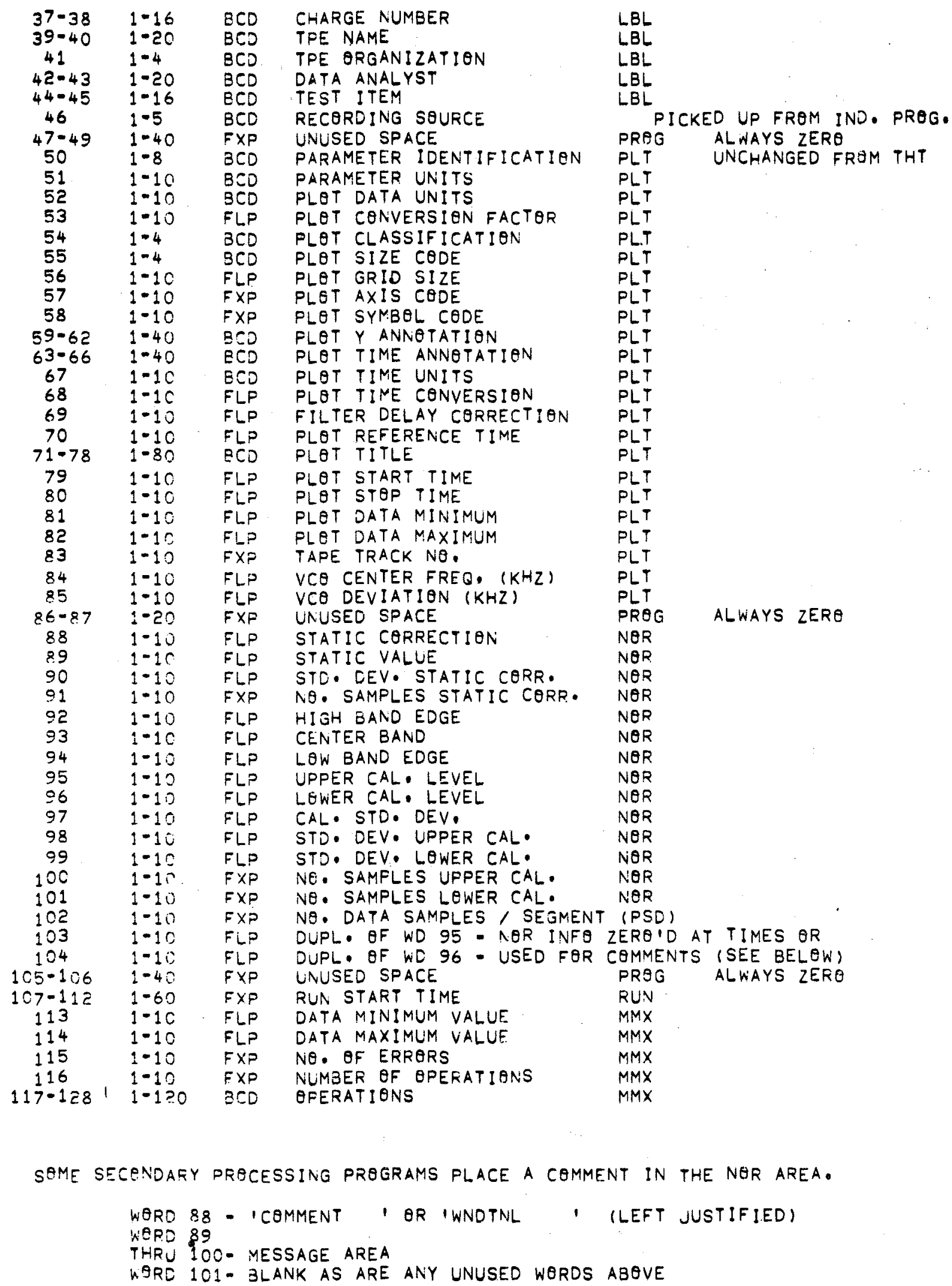




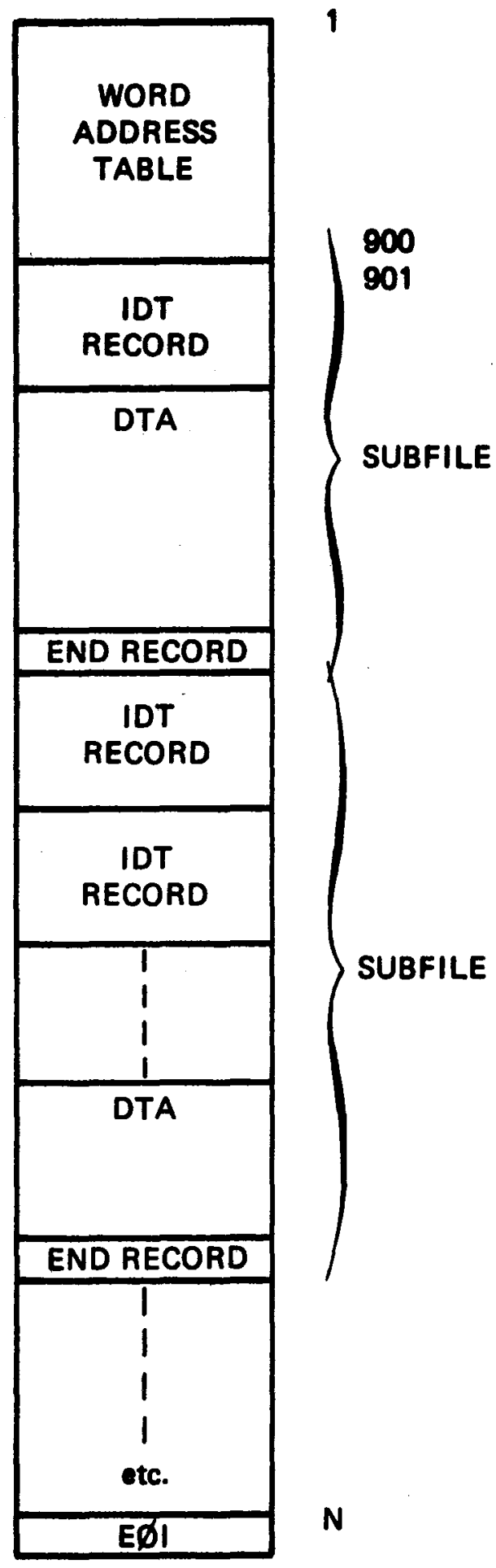

Figure A-2. File Structure 
The input file to program IMPACT must be a word-addressable Master Disc File as described on page 35. This file contains the data recovered from the high-speed photographic film. The following information is required for each test.

\begin{tabular}{|c|c|c|c|}
\hline Symbol & Channel Identifier & Units & Remarks \\
\hline$x$ & $\mathrm{x}$ & Feet & \multirow{3}{*}{$\begin{array}{l}\text { Location of the origin } \\
\text { of the body fixed co- } \\
\text { ordinate system }\end{array}$} \\
\hline $\mathrm{y}$ & $\mathrm{Y}$ & Feet & \\
\hline z & Z & Feet & \\
\hline$\psi$ & Yaw & Degrees & \multirow{3}{*}{$\begin{array}{l}\text { Euler angles which } \\
\text { describe angular } \\
\text { position of body }\end{array}$} \\
\hline$\theta$ & Pitch & Degrees & \\
\hline$\phi$ & Roll & Degrees & \\
\hline
\end{tabular}

Parameter Card Input

Parameter Cards

1. Control information may be entered in one of three card formats:

a. The fixed-field card-identifier format consists of a 1-to-5-character card identifier beginning in Column 1, followed by one or more fixed-data fields as defined by the program.

b. The free-field card-identifier format corresponds to a fixed-field card and has the following syntax:

$\mathrm{ID}=$ data field, data field, ..., data field

where the card identifier ID may begin in any column. $\mathrm{Blank}$ fields are appended or surplus fields deleted from the right, if necessary, so that a free-field card defines the same parameters as the fixed-field card with the same identifier.

c. The parameter-identifier format has the following syntax: 


$$
\mathrm{ID}_{1}=\text { data field, } \mathrm{ID}_{2}=\text { data field, } \ldots, \mathrm{I}_{\mathrm{n}}=\text { data field }
$$

where $\mathrm{I}_{j}$ is a 1-to-10-character parameter identifier defined by the program.

2. Three types of data fields are used.

a. Integer - A number written in I format may appear anywhere in the field.

b. Real - A number written in I, F, or E format may appear anywhere in the field.

c. Name - A 1-to-10-character alphanumeric parameter may appear anywhere in the field.

Internal blank characters are ignored in all three types of fields.

\section{Parameter Card Description}

The ten parameter cards defined for program IMPACT have the following card identifiers: CHAN, TIME, SK, SK1, SK2, MP, MP1, MPR, MPR1, and PASS. The information for all of the cards except the PASS card may be entered in any of the three formats described on pages 40 and 41 . The PASS card information can be entered only in the fixed-field format. Each card is described in the fixed-field, cardidentifier format.

1. CHAN card - Identifies up to seven channels of data to be selected for input.

\begin{tabular}{|c|c|c|c|c|}
\hline Column & $\begin{array}{c}\text { Input } \\
\text { Parameter } \\
\text { Identifier } \\
\end{array}$ & Type & \multicolumn{2}{|c|}{ Description } \\
\hline $1-4$ & -- & -- & CHAN & \\
\hline $5-10$ & $-\infty$ & - & Blank & \\
\hline $11-20$ & ID1 & Name & Channel & Name \\
\hline $21-30$ & ID2 & $" 1$ & $" 1$ & $" 1$ \\
\hline $31-40$ & ID3 & $"$ & $"$ & $" 1$ \\
\hline $41-50$ & ID4 & $" 1$ & $"$ & $"$ \\
\hline $51-60$ & ID5 & $" 1$ & $"$ & $"$ \\
\hline $61-70$ & ID6 & $" 1$ & 11 & $" 1$ \\
\hline $71-80$ & D7 & $" 1$ & $"$ & " \\
\hline
\end{tabular}


2. TIME card - Defines the time span of interest and the time increment.

\begin{tabular}{|c|c|c|c|}
\hline Column & $\begin{array}{l}\text { Parameter } \\
\text { Identifier } \\
\end{array}$ & Type & Description \\
\hline $1-4$ & -- & -- & TIME \\
\hline $5-10$ & -- & -- & Blank \\
\hline $11-20$ & START & Real & $\begin{array}{l}\text { Time in seconds, refer- } \\
\text { enced to plot reference } \\
\text { time. Default is time of } \\
\text { first sample. }\end{array}$ \\
\hline $21-30$ & STOP & Réal & $\begin{array}{l}\text { Time in seconds, refer- } \\
\text { enced to plot reference } \\
\text { time. Default is time of } \\
\text { last sample. }\end{array}$ \\
\hline $31-40$ & DELT & Real & $\begin{array}{l}\text { Time increment for inter- } \\
\text { polation. A value of } 0 \\
\text { indicates data will not be } \\
\text { interpolated. }\end{array}$ \\
\hline $41-50$ & $\mathrm{NPT}$ & Integer & $\begin{array}{l}\text { Maximum number of points } \\
\text { to be taken. (Not imple- } \\
\text { mented) }\end{array}$ \\
\hline $51-80$ & $-\infty$ & $-\infty$ & Blank \\
\hline
\end{tabular}

3. SK card - Defines the locations of point 1 and point 2 in the body at which velocities and accelerations are to be computed.

\begin{tabular}{|c|c|c|c|c|}
\hline Symbol & Column & Identifier & Type & Description \\
\hline & $1-2$ & - & -- & SK \\
\hline & $3-10$ & -- & -- & Blank \\
\hline$S_{1 x}$ & $11-20$ & SKX1 & Real & $\begin{array}{l}X \text {-coordinate of first } \\
\text { point in body }\end{array}$ \\
\hline$S_{1 y}$ & $21-30$ & SKY1 & Real & $\begin{array}{l}Y \text {-coordinate of first } \\
\text { point in body }\end{array}$ \\
\hline $\mathrm{S}_{1 z}$ & $31-40$ & SKZ1 & Real & $\begin{array}{l}Z \text {-coordinate of first } \\
\text { point in body }\end{array}$ \\
\hline$S_{2 x}$ & $41-50$ & SKX2 & Real & $\begin{array}{l}X \text {-coordinate of second } \\
\text { point in body }\end{array}$ \\
\hline
\end{tabular}




$\begin{array}{lcccc}\frac{\text { Symbol }}{\mathrm{S}_{2 \mathrm{y}}} & \frac{\text { Column }}{51-60} & \frac{\text { Identifier }}{\text { SKY2 }} & \frac{\text { Type }}{\text { Real }} & \begin{array}{l}\text { Description } \\ \begin{array}{l}\text { Y-coordinate of second } \\ \text { point in body }\end{array} \\ \mathrm{S}_{2 \mathrm{z}}\end{array} \\ 61-70 & \text { SKZ2 } & \text { Real } & \begin{array}{l}\text { Z-coordinate of second } \\ \text { point in body }\end{array} \\ & 71-80 & -- & -- & \text { Blank }\end{array}$

4. SKI card - Defines the locations of point 3 and point 4 in the body at which velocities and acceleration are to be computed.

\begin{tabular}{|c|c|c|c|c|}
\hline Symbol & Column & $\begin{array}{l}\text { Parameter } \\
\text { Identifier }\end{array}$ & Type & Description \\
\hline & $1-3$ & - & $-\infty$ & SK1 \\
\hline & $4-10$ & -- & -- & Blank \\
\hline$S_{3 x}$ & $11-20$ & SKX3 & Real & $\begin{array}{l}X \text {-coordinate of third } \\
\text { point in body }\end{array}$ \\
\hline$s_{3 y}$ & $21-30$ & SKY3 & Real & $\begin{array}{l}\mathrm{Y} \text {-coordinate of third } \\
\text { point in body }\end{array}$ \\
\hline$S_{3 z}$ & $31-40$ & SKZ3 & Real & $\begin{array}{l}Z \text {-coordinate of third } \\
\text { point in body }\end{array}$ \\
\hline$S_{4 x}$ & $41-50$ & SKX4 & Real & $\begin{array}{l}X \text {-coordinate of fourth } \\
\text { point in body }\end{array}$ \\
\hline$S_{4 y}$ & $51-60$ & SKY4 & Real & $\begin{array}{l}\mathrm{Y} \text {-coordinate of fourth } \\
\text { point in body }\end{array}$ \\
\hline \multirow[t]{2}{*}{$S_{4 z}$} & $61-70$ & SKZ4 & Real & $\begin{array}{l}\text { Z-coordinate of fourth } \\
\text { point in body }\end{array}$ \\
\hline & $71-80$ & -- & -- & Blank \\
\hline
\end{tabular}


5. SL 2 card - Defines the locations of point 5 and point 6 in the body at which velocities and accelerations are to be computed.

\begin{tabular}{|c|c|c|c|c|}
\hline Symbol & Column & $\begin{array}{l}\text { Parameter } \\
\text { Identifier } \\
\end{array}$ & Type & Description \\
\hline & $1-3$ & -- & -- & SK2 \\
\hline & $4-10$ & -- & -- & Blank \\
\hline$S_{5 x}$ & $11-20$ & SKX5 & Real & $\begin{array}{l}X \text {-coordinate of fifth } \\
\text { point in body }\end{array}$ \\
\hline$S_{5 y}$ & $21-30$ & SKY5 & Real & $\begin{array}{l}Y \text {-coordinate of fifth } \\
\text { point in body }\end{array}$ \\
\hline$S_{5 z}$ & $31-40$ & SKZ5 & Real & $\begin{array}{l}\mathrm{Z} \text {-coordinate of fifth } \\
\text { point in the body }\end{array}$ \\
\hline$S_{6 x}$ & $41-50$ & SKX6 & Real & $\begin{array}{l}X \text {-coordinate of sixth } \\
\text { point in body }\end{array}$ \\
\hline$s_{6 y}$ & $51-60$ & SKY6 & Real & $\begin{array}{l}\mathrm{Y} \text {-coordinate of sixth } \\
\text { point in body }\end{array}$ \\
\hline \multirow[t]{2}{*}{$S_{6 z}$} & $61-70$ & SKZ6 & Real & $\begin{array}{l}\mathrm{Z} \text {-coordinate of sixth } \\
\text { point in body }\end{array}$ \\
\hline & $71-80$ & -- & -- & Blank \\
\hline
\end{tabular}

6. MP card - Defines the mass properties of the body at beginning, of data.

\begin{tabular}{|c|c|c|c|c|}
\hline Symbol & Column & $\begin{array}{l}\text { Parameter } \\
\text { Identifier } \\
\end{array}$ & Type & Description \\
\hline & $1-2$ & -- & -- & MP \\
\hline & $3-10$ & -- & - & Blank \\
\hline & $11-20$ & $\mathrm{~T} 1$ & Real & $\begin{array}{l}\text { Time for application of } \\
\text { mass property data of } \\
\text { body }\end{array}$ \\
\hline$\overline{\mathrm{m}}$ & $21-30$ & BMASS1 & Real & Mass of body in slugs \\
\hline$c_{x}$ & $31-40$ & CMX1 & Real & $\begin{array}{l}X \text {-coordinate of center } \\
\text { of mass in feet }\end{array}$ \\
\hline$c_{y}$ & $41-50$ & CMY1 & Real & $\begin{array}{l}Y \text {-coordinate of center } \\
\text { of mass in feet }\end{array}$ \\
\hline$c_{z}$ & $51-60$ & CMZ1 & Real & $\begin{array}{l}Z \text {-coordinate of center } \\
\text { of mass in feet }\end{array}$ \\
\hline$I_{x x}$ & $61-70$ & $\mathrm{XIX} 1$ & Real & $\mathrm{X}$-moment of inertia \\
\hline $\mathrm{I}_{\mathrm{yy}}$ & $71-80$ & YIY1 & Real & $\mathrm{Y}$-moment of inertia \\
\hline
\end{tabular}


7. MP1 card - Continuation of the MP card to define the remaining mass properties of the body.

\begin{tabular}{|c|c|c|c|c|}
\hline Symbol & Column & $\begin{array}{l}\text { Parameter } \\
\text { Identifier }\end{array}$ & Type & Description \\
\hline & $1-3$ & -- & -- & MP1 \\
\hline & $4-10$ & -- & -- & $\mathrm{Blank}$ \\
\hline & $11-20$ & ZIZ1 & Real & $Z$-moment of inertia \\
\hline & $21-30$ & $\mathrm{XIY} 1$ & Real & $X Y$-product of inertia \\
\hline & $31-40$ & YIZ1 & Real & $\mathrm{YZ}$-product of inertia \\
\hline$z x=I x z$ & $41-50$ & ZIX1 & Real & ZX-product of inertia \\
\hline & $51-80$ & -- & -- & Blank \\
\hline
\end{tabular}

8. MPR card - Defines the second set of mass properties of the body and the time these values are to be used.

\begin{tabular}{|c|c|c|c|c|}
\hline Symbol & Column & $\begin{array}{l}\text { Parameter } \\
\text { Identifier } \\
\end{array}$ & Type & Description \\
\hline & $1-3$ & - & -- & MPR \\
\hline & $4-10$ & -- & -- & Blank \\
\hline & $11-20$ & $\mathrm{~T} 2$ & Real & $\begin{array}{l}\text { Time for application } \\
\text { of this set of mass } \\
\text { property data }\end{array}$ \\
\hline$\overline{\mathrm{m}}$ & $21-30$ & BMASS2 & Real & $\begin{array}{l}\text { Mass of the body in } \\
\text { slugs }\end{array}$ \\
\hline$c_{\mathrm{x}}$ & $31-40$ & CMX2 & Real & $\begin{array}{l}X \text {-coordinate in feet } \\
\text { of center of mass }\end{array}$ \\
\hline$c_{y}$ & $41-50$ & CMY2 & Real & $\begin{array}{l}\mathrm{Y} \text {-coordinate in feet } \\
\text { of center of mass }\end{array}$ \\
\hline$c_{z}$ & $51-60$ & CMZ2 & Real & $Z$-coordinate in feet \\
\hline$I_{x x}$ & $61-70$ & XIX2 & Real & $\mathrm{X}$-moment of inertia \\
\hline $\mathrm{I}_{\mathrm{yy}}$ & $71-80$ & YIY2 & Real & $\mathrm{Y}$-moment of inertia \\
\hline
\end{tabular}


9. MPR1 card - Continuation of the MPR card to define the remaining mass properties of the body.

\begin{tabular}{|c|c|c|c|c|}
\hline Symbol & Column & $\begin{array}{l}\text { Parameter } \\
\text { Identifier }\end{array}$ & Type & Description \\
\hline & $1-4$ & -- & -- & MPR1 \\
\hline & $5-10$ & -- & -- & Blank \\
\hline $\mathrm{I}_{\mathrm{zz}}$ & $11-20$ & ZIZ2 & Real & Z-moment of inertia \\
\hline$I_{x y}$ & $21-30$ & $\mathrm{X} \Gamma \mathrm{Y} 2$ & Real & $\mathrm{X}-\mathrm{Y}$ product of inertia \\
\hline $\mathrm{I}_{\mathrm{yz}}$ & $31-40$ & YIZ2 & Real & $\mathrm{Y}-\mathrm{Z}$ product of inertia \\
\hline \multirow[t]{2}{*}{$I_{z x}$} & $41-50$ & ZIX2 & Real & $\mathrm{Z}-\mathrm{X}$ product of inertia \\
\hline & $51-80$ & -- & -- & Blank \\
\hline
\end{tabular}

10. PASS card - Indicates the end of a set of parameter cards.

\begin{tabular}{cccl} 
Column & $\begin{array}{c}\text { Parameter } \\
\text { Identifier }\end{array}$ & Type & \multicolumn{1}{c}{ Description } \\
\cline { 2 - 3 } $1-4$ & - & -- & PASS \\
5 & -- & -- & Blank \\
$6-10$ & -- & Integer & $\begin{array}{l}\text { Fatal error limit. } \\
\text { Default }=10\end{array}$ \\
$11-15$ & -- & Integer & $\begin{array}{l}\text { Nonfatal error limit. } \\
\text { Default }=20\end{array}$
\end{tabular}

Parameter Card Organization

The parameter cards are organized into a set using any or all of the cards described on pages 42 through 46 (sections 2 through 10) and terminated by a PASS card. The cards are order-independent. The parameters read in for a pass remain until they are redefined by a succeeding set of parameter cards. Parameters associated with continuation cards (MP1 and MPR1) are blanked when the primary card MP and MPR are read. 


\section{Diagnostic Messages}

All diagnostic information is listed on a file named TAPE61. Program DUMP61 lists and summarizes the diagnostic information.

Errors are classified into two types, "fatal" and "nonfatal." A fatal error is one in which one or more channels of information cannot be computed. A nonfatal error is one which can be corrected by substitution of a default option. The data is processed, but the result may not be what was originally requested.

The first and second fields on the PASS card are the fatal and nonfatal error limits, respectively. If either error limit is reached, the program will "exit."

Output Data File

The data computed by program IMPACT is written out in seven or more subfiles in Division 8411's standard word addressable Master Disc File format as described on pages 36-39. The IDT records have been modified to accompany the output data so that the MDF can be easily read and the data plotted by the program MDFPLT. The file can also be used as input to any of the secondary data processing programs on the permanent library file, DRWAL IB.

The content of the file is as follows:

Subfile No. 1

Channel

\begin{tabular}{|c|c|c|c|}
\hline Symbol & Identifier & Units & Remarks \\
\hline $\mathrm{x}$ & $\mathrm{X}(\mathrm{SM})$ & Feet & Smoothed $\mathrm{x}$ coordinate of the body \\
\hline $\mathrm{y}$ & $\mathrm{Y}(\mathrm{SM})$ & Feet & Smoothed y coordinate of the body \\
\hline $\mathrm{z}$ & $Z(\mathrm{SM})$ & Feet & Smoothed $\mathrm{z}$ coordinate of the body \\
\hline$\psi$ & PSI(SM) & Degrees & Smoothed yaw angle of the body \\
\hline$\theta$ & THE(SM) & Degrees & Smoothed pitch angle of the body \\
\hline$\phi$ & PHI(SM) & Degrees & Smoothed roll angle of the body \\
\hline
\end{tabular}


Subfile No. 2

Channel

\begin{tabular}{|c|c|c|c|}
\hline Symbol & Identifier & Units & Remarks \\
\hline$\dot{x}$ & $\mathrm{XD}$ & $\mathrm{FT} / \mathrm{SEC}$ & $\psi$ inertial component of velocity \\
\hline$\ddot{\mathbf{x}}$ & $\mathrm{XDD}$ & $\mathrm{FT} / \mathrm{S} / \mathrm{S}$ & $\mathrm{X}$ inertial component of acceleration \\
\hline$\dot{\mathrm{y}}$ & $\mathrm{YD}$ & FT/SEC & $Y$ inertial component of velocity \\
\hline$\ddot{y}$ & $\mathrm{YDD}$ & $\mathrm{FT} / \mathrm{S} / \mathrm{S}$ & $Y$ inertial component of acceleration \\
\hline$\dot{\mathrm{z}}$ & $\mathrm{ZD}$ & FT/SEC & $Z$ inertial component of velocity \\
\hline$\ddot{z}$ & $\mathrm{ZDD}$ & $\mathrm{FT} / \mathrm{S} / \mathrm{S}$ & $\mathrm{Z}$ inertial component of acceleration \\
\hline$\dot{\theta}$ & THED & $\mathrm{DEG} / \mathrm{SEC}$ & Time rate of change of pitch \\
\hline$\dot{\psi}$ & PSID & $\mathrm{DEG} / \mathrm{SEC}$ & Time rate of change of yaw \\
\hline$\dot{\phi}$ & PHID & $\mathrm{DEG} / \mathrm{SEC}$ & Time rate of change of roll \\
\hline $\mathrm{p}$ & PP & DEG/SEC & \\
\hline q & QQ & $\mathrm{DEG} / \mathrm{SEC}$ & $\begin{array}{l}\text { Body components of angular } \\
\text { velocity }\end{array}$ \\
\hline$r$ & $\mathrm{RR}$ & $\mathrm{DEG} / \mathrm{SEC}$ & \\
\hline$\dot{\mathrm{p}}$ & PPD & $\mathrm{DEG} / \mathrm{S} / \mathrm{S}$ & \\
\hline$\dot{q}$ & QQD & $\mathrm{DEG} / \mathrm{S} / \mathrm{S}$ & $\begin{array}{l}\text { Body components of angular } \\
\text { acceleration }\end{array}$ \\
\hline$\dot{\mathbf{r}}$ & RRD & $\mathrm{DEG} / \mathrm{S} / \mathrm{S}$ & \\
\hline
\end{tabular}

Subfile No. 3

\begin{tabular}{|c|c|c|c|}
\hline Symbol & $\begin{array}{c}\text { Channel } \\
\text { Identifier } \\
\end{array}$ & Units & Remarks \\
\hline $\mathrm{u}$ & UU & FT/SEC & \multirow{3}{*}{ Body components of velocity } \\
\hline $\mathrm{v}$ & VV & $\mathrm{FT} / \mathrm{SEC}$ & \\
\hline$w$ & WW & FT / SEC & \\
\hline$\nu$ & NU & FT/SEC & Magnitude of velocity \\
\hline$\dot{\mathrm{u}}$ & UUD & $\mathrm{FT} / \mathrm{S} / \mathrm{S}$ & \multirow{3}{*}{ Body components of acceleration } \\
\hline$\dot{\mathrm{v}}$ & VVD & $\mathrm{FT} / \mathrm{S} / \mathrm{S}$ & \\
\hline$\dot{\mathrm{w}}$ & WWD & $\mathrm{FT} / \mathrm{S} / \mathrm{S}$ & \\
\hline$\zeta$ & ZETA & DEGREES & Azimuth angle \\
\hline$\beta$ & BETA & DEGREES & Flight path angle \\
\hline$\hat{\alpha}$ & $\mathrm{ALPH}$ & DEGREES & Total angle of attack \\
\hline$\hat{\phi}$ & PHIH & DEGREES & Windward meridian angle \\
\hline
\end{tabular}


Subfile No. 4 or 4 and 5 (Depending on the number of points selected.)

\begin{tabular}{|c|c|c|c|}
\hline Symbol & $\begin{array}{c}\text { Channel } \\
\text { Identifier }\end{array}$ & Units & Remarks \\
\hline $\mathrm{U}_{1}$ & $\mathrm{U} 1$ & $\mathrm{FT} / \mathrm{SEC}$ & \\
\hline$v_{1}$ & $\mathrm{~V} 1$ & $\mathrm{FT} / \mathrm{SEC}$ & $\begin{array}{l}\text { Body components of velocity at } \\
\text { first selected point of the body }\end{array}$ \\
\hline $\mathrm{w}_{1}$ & W1 & $\mathrm{FT} / \mathrm{SEC}$ & \\
\hline$\nu_{1}$ & NU1 & $\mathrm{FT} / \mathrm{SEC}$ & Magnitude of velocity at $1^{\text {st }}$ point \\
\hline - & - & - & \\
\hline • & • & $\cdot$ & \\
\hline $\mathrm{U}_{\mathrm{k}}$ & & $\mathrm{FT} / \mathrm{SEC}$ & \\
\hline $\mathrm{v}_{\mathrm{k}}^{\mathrm{k}}$ & & FT/SEC & $\begin{array}{l}\text { Body components of velocity at } k^{\text {th }} \\
\text { selected point of the body }\end{array}$ \\
\hline $\mathrm{w}_{\mathrm{k}}$ & & FT/SEC & \\
\hline$\nu_{\mathrm{k}}$ & & FT/SEC & Magnitude of velocity at $\mathrm{k}^{\mathrm{th}}$ point \\
\hline
\end{tabular}

Subfile No. 5 or 6 and 7

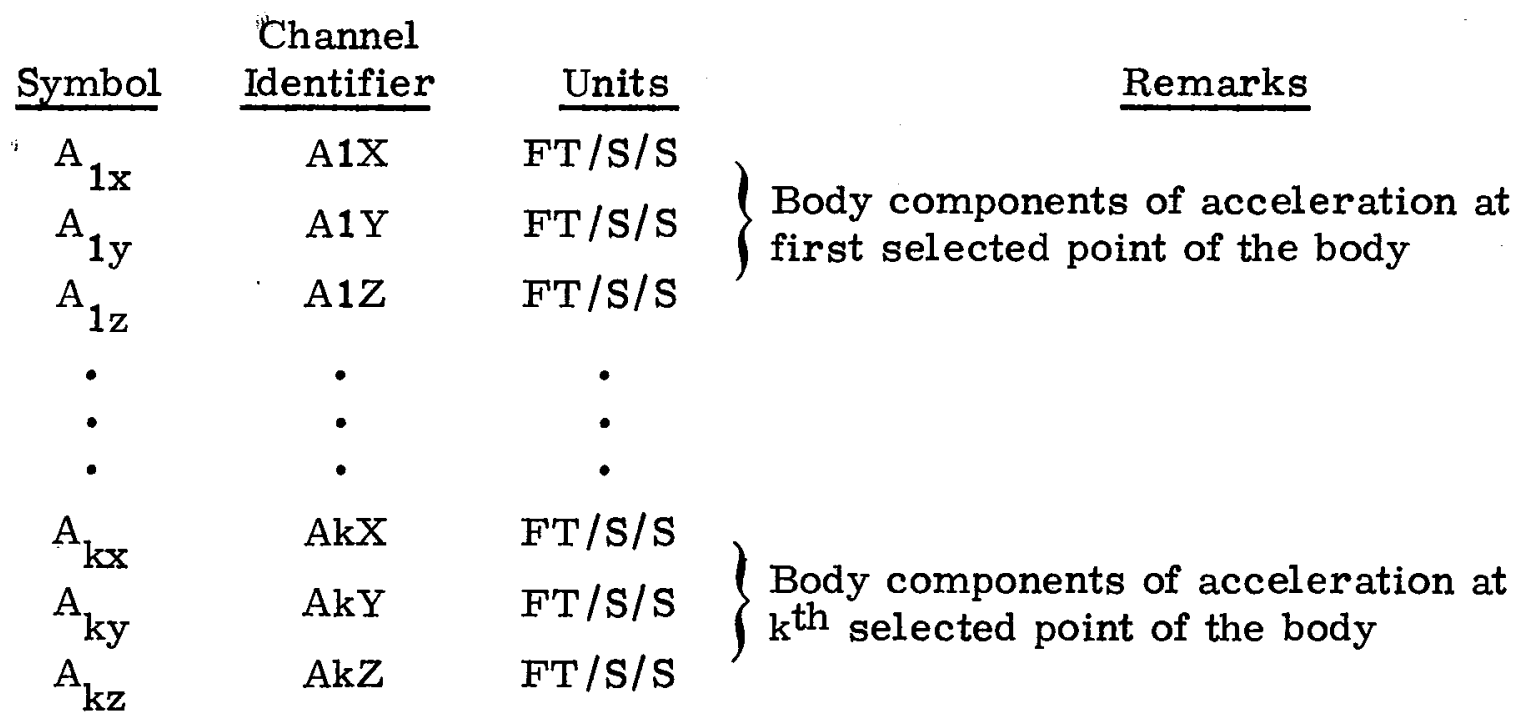

NOTE: The program has the capability of computing velocities and accelerations for up to six selected points in the body. The number of subfiles required for data output will depend on the number of points selected. If only two locations are selected, the data is written out in two subfiles. One: subfile contains the velocities; the other contains the accelerations. If six body locations are selected, a total of four subfiles are written: two containing velocity data and two containing acceleration data. 
Subfile No. 6 or 8

\begin{tabular}{|c|c|c|c|}
\hline Symbol & $\begin{array}{l}\text { Channel } \\
\text { Identifier }\end{array}$ & Units & Remarks \\
\hline$g_{x}$ & GX & SL UG-FT/S & \multirow{3}{*}{$\begin{array}{l}\text { Body components of linear } \\
\text { momentum }\end{array}$} \\
\hline$g_{y}$ & GY & SLUG-FT/S & \\
\hline$g_{z}^{y}$ & GZ & SLUG-FT/S & \\
\hline$h_{x}$ & $\mathrm{HX}$ & SLUG-FT/S & \multirow{3}{*}{$\begin{array}{l}\text { Body components of angular } \\
\text { momentum }\end{array}$} \\
\hline$h_{y}$ & HY & SLUG-FT/S & \\
\hline $\mathrm{h}_{\mathrm{z}}$ & $\mathrm{HZ}$ & SL UG-FT/S & \\
\hline $\mathrm{T}$ & $\mathrm{KE}$ & FT-LBS & Kinetic energy of the body \\
\hline $\mathrm{V}$ & $\mathrm{PE}$ & FT-LBS & Potential energy of the body \\
\hline $\mathrm{E}$ & $\mathrm{TE}$ & FT-LBS & Total energy of the body \\
\hline $\mathrm{X}$ & BX & LBS & \multirow{3}{*}{$\begin{array}{l}\text { Body components of external } \\
\text { force }\end{array}$} \\
\hline $\mathrm{Y}$ & BY & LBS & \\
\hline $\mathrm{Z}$ & $\mathrm{BZ}$ & LBS & \\
\hline$f_{x}$ & FX & LBS & \multirow{3}{*}{$\begin{array}{l}\text { Inertial components of external } \\
\text { force }\end{array}$} \\
\hline$f_{y}$ & FY & LBS & \\
\hline$f_{z}$ & FZ & LBS & \\
\hline $\mathrm{L}$ & LL & FT-LBS & $\begin{array}{l}\mathrm{X} \text { body component of external } \\
\text { moment }\end{array}$ \\
\hline
\end{tabular}

Subfile No, 7 or 9

Channel

Symbol Identifier

M

MM

Units

Remarks

FT-LBS

$\mathrm{y}$ body component of external moments

$\mathrm{N}$

NN

FT-LBS

$z$ body component of external moments

$\ell$
$\mathrm{m}$
$\mathrm{n}$
$\mathrm{G}_{\mathrm{x}}$
$\mathrm{G}_{\mathrm{y}}$
$\mathrm{G}_{\mathrm{z}}$

SL

SM

$\mathrm{SN}$

FT-LBS

FT-LBS

Inertial components of external

FT-LBS

GGX SLUG-FT/S

GGY

GGZ

$\left.\begin{array}{l}\text { SL UG-FT/S } \\ \text { SL UG-FT/S }\end{array}\right\}$

Inertial components of 1 inear momentum 
Subfile No. 7 or 9 (continued)

\begin{tabular}{|c|c|c|c|}
\hline Symbol & $\begin{array}{c}\text { Channel } \\
\text { Identifier }\end{array}$ & Units & Remarks \\
\hline $\mathrm{H}_{\mathrm{x}}$ & HHX & SLUG-FT/S & \\
\hline$H_{y}^{x}$ & HHY & SLUG-FT/S & $\begin{array}{l}\text { Inertial components of angular } \\
\text { momentum }\end{array}$ \\
\hline $\mathrm{H}_{\mathrm{z}}$ & $\mathrm{HHZ}$ & SLUG-FT/S & \\
\hline
\end{tabular}

Program Execution

Program IMPACT is on a permanent library named MACHL IB. The program also uses subroutines that are located on DRWALIB. To load and execute program IMPACT, both libraries must be attached as illustrated.

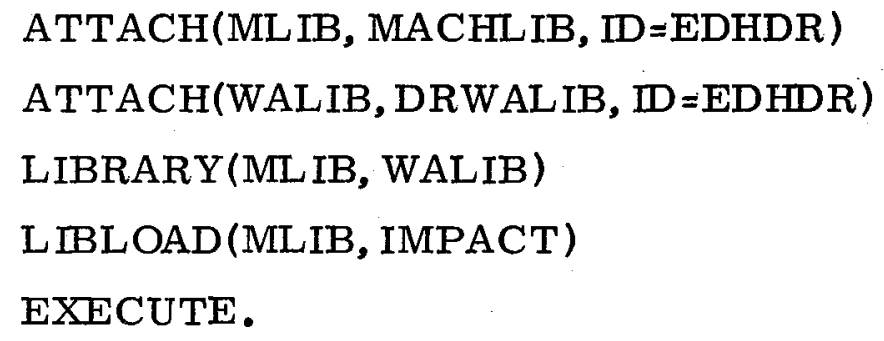

The program is looking for an input file with a logical name MDF; therefore when attaching the data file it must have the logical file name $\mathrm{MDF}$.

\section{ATTACH(MDF, IMP129A, DD=B77DTA)}

The output file has a logical file name MDF1. Any subsequent use of this file may require that the file be given a new logical file name to agree with the file name internal to the program. If a person wants to plot the data from the output file, it would have to be given the new name MDF by using the following SCOPE cards.

FILE(MDF, L FN = MDFL)

LIBL $\varnothing A D$ (WALIB, MDFPLT)

LDSET(FILES $=$ MDF)

LDSET(LIB=FTNL IBY)

EXECUTE.

PLT75. 
The CDC 6600 SCOPE cards are followed by an $\mathrm{E} \phi \mathrm{R}(7,8,9)$ card. This card is followed by the input parameter cards which are in turn followed by another $\mathrm{E} \phi \mathrm{R}$ card.

$$
\begin{aligned}
& J \phi B \text { card } \\
& \text { SCOPE cards } \\
& { }^{7}{ }_{9} \mathrm{E} \phi \mathrm{R} \text { card } \\
& \text { parameter cards } \\
& { }^{7}{ }_{9} \mathrm{E} \phi \mathrm{R} \text { card } \\
& { }^{6}{ }_{7_{9}} \text { End of job card. }
\end{aligned}
$$

To accomplish the smoothing and compute the first and second derivatives, the subroutine SM $\phi \phi$ from the Sandia Mathematical Program Library ${ }^{1}$ is used. The subroutine computes the parameters of a smoothing spline fit to the data. This subroutine uses an array of error estimates which provide for a looser or tighter fit of the data. The results of the numerical differentiation are not the most satisfactory; however, they are about as good as we can obtain with the techniques now available. It is necessary to make several runs with adjusted error estimates to produce reasonable derivatives.

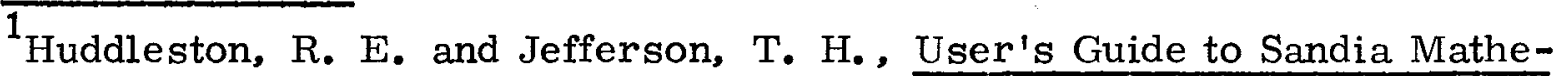
matical Program Library at Livermore, Sandia Laboratories, Livermore, SAND 76-8209, March 1976.
} 


\section{APPENDIX B--SAMPLE DATA PLOTS}

Appendix B contains some sample plots of the more meaningful data, computed by the program IMPACT, such as the body components of linear and angular velocity, the potential and kinetic energy, body components of external and inertial force, and the inertial components of linear and angular momentum. Not shown is the diagnostic information computed by the program for each of the sample plots.

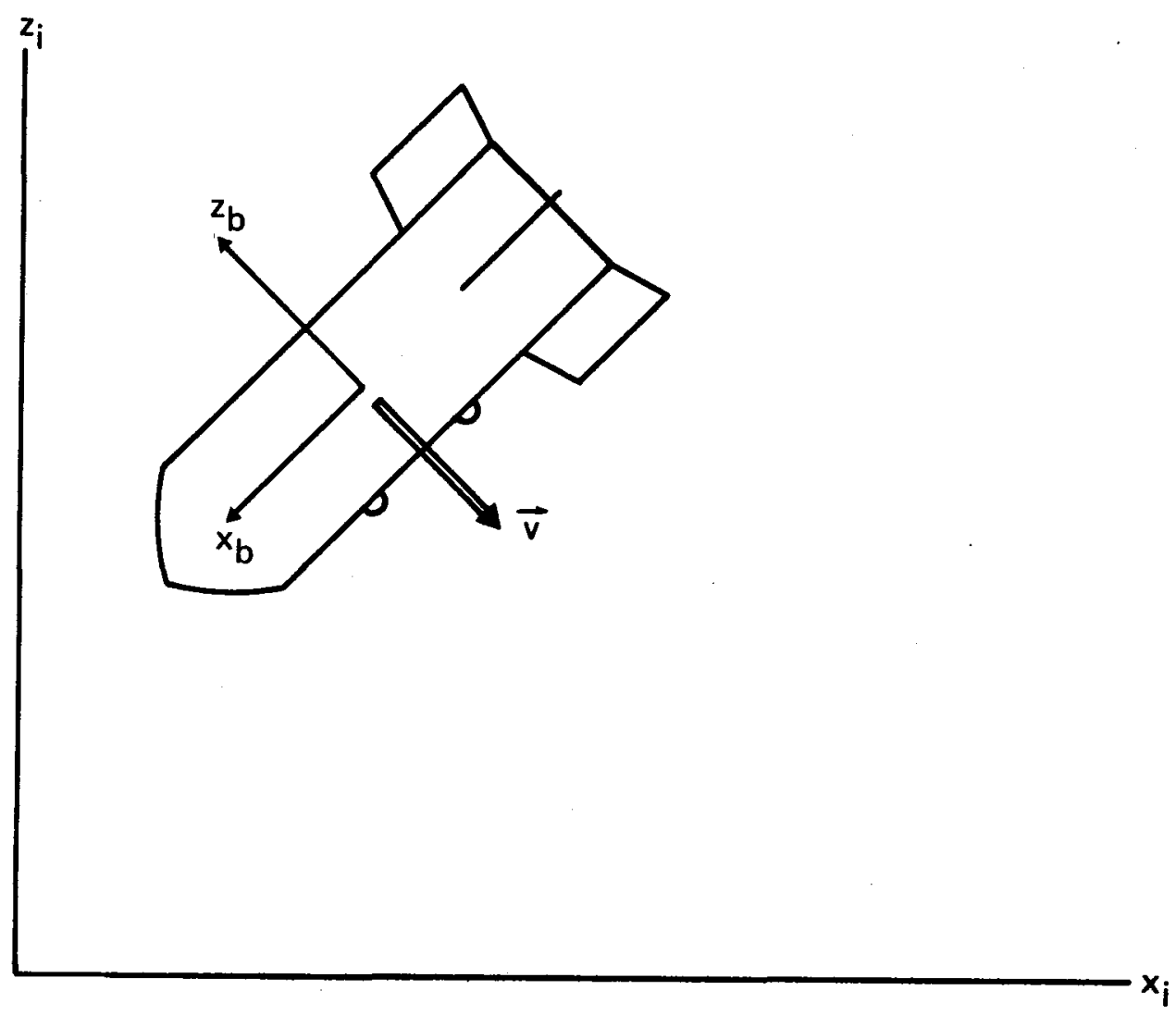

Figure B-1. Initial Conditions for ITU-130A. 

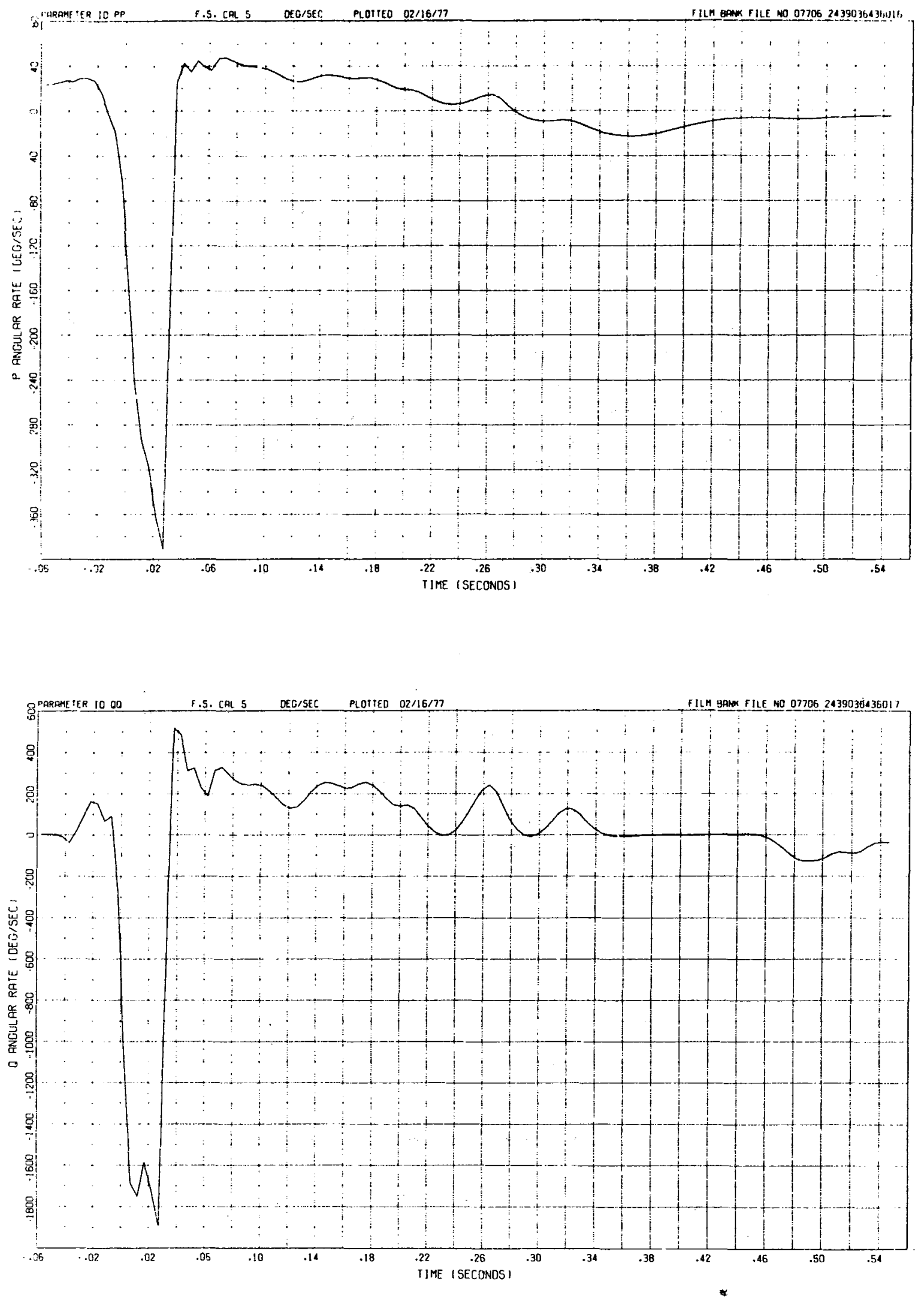

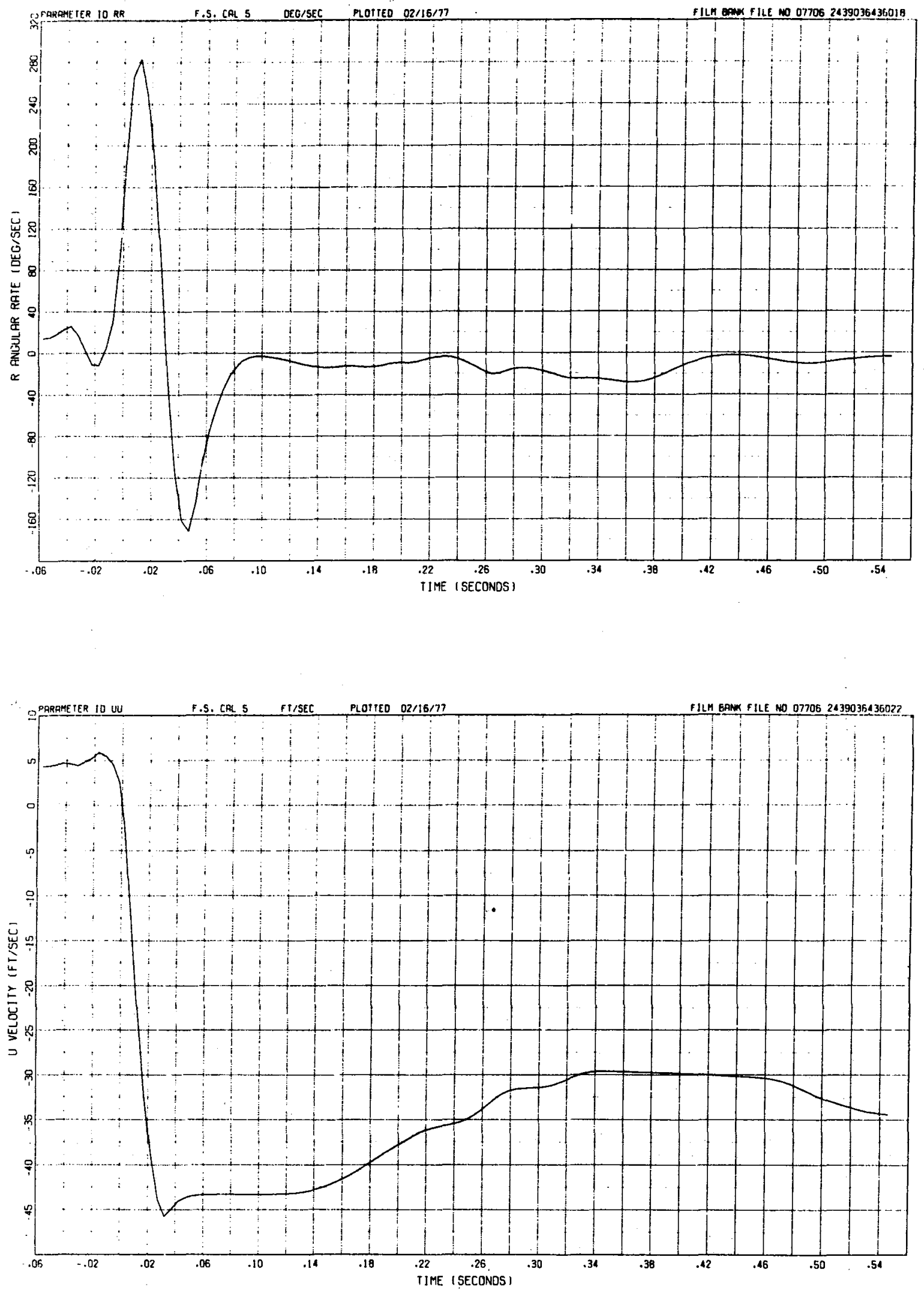

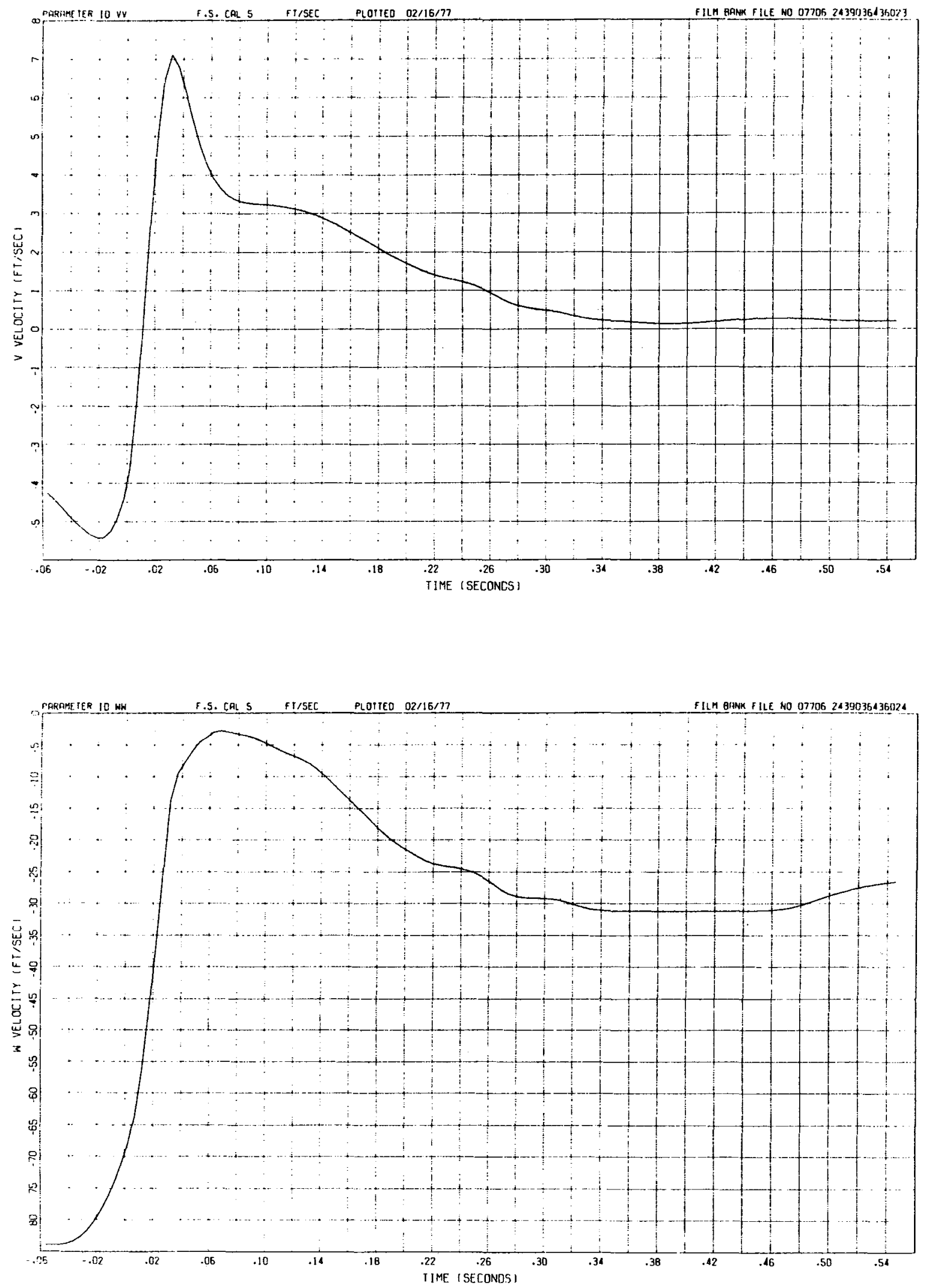

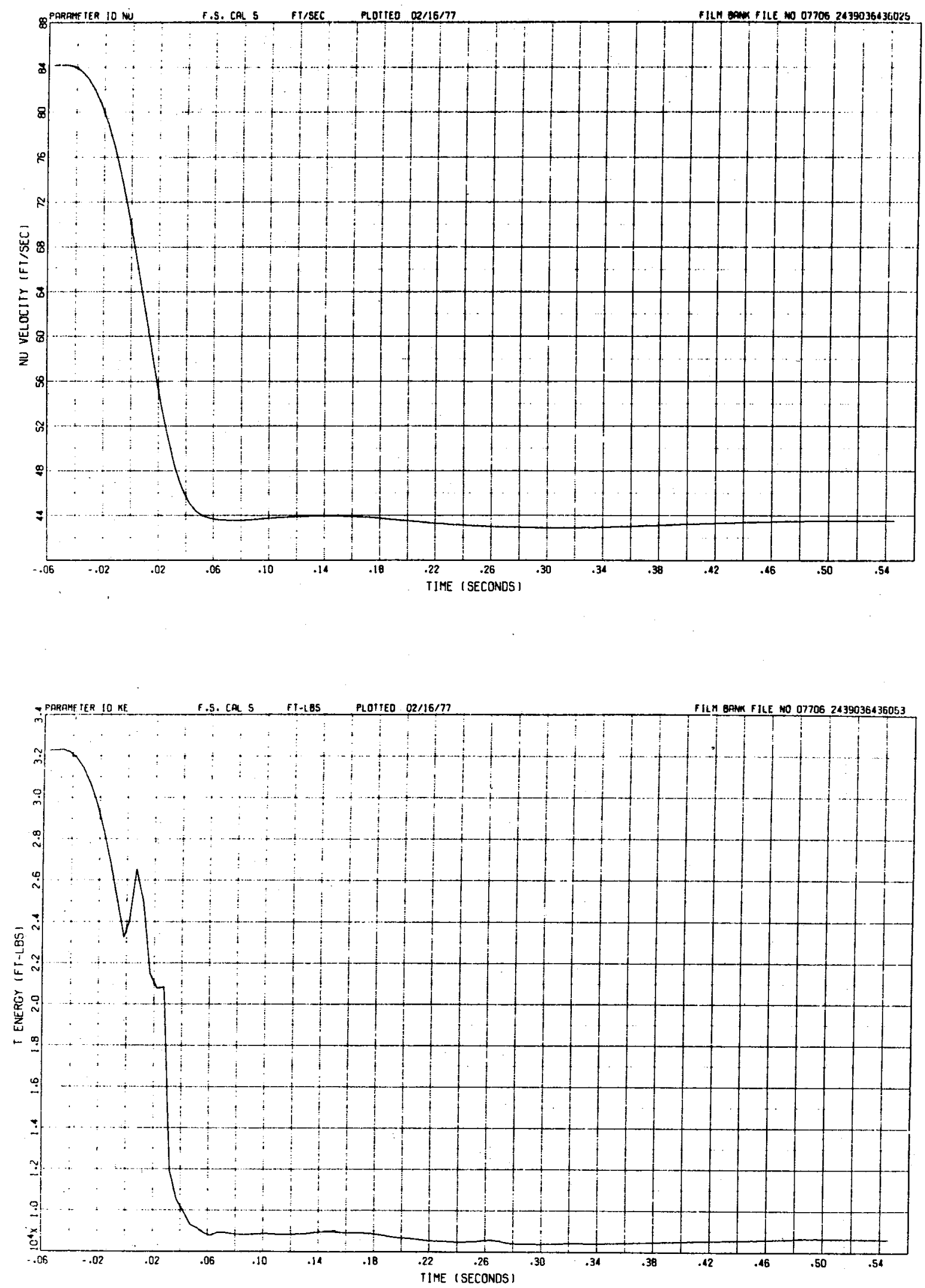

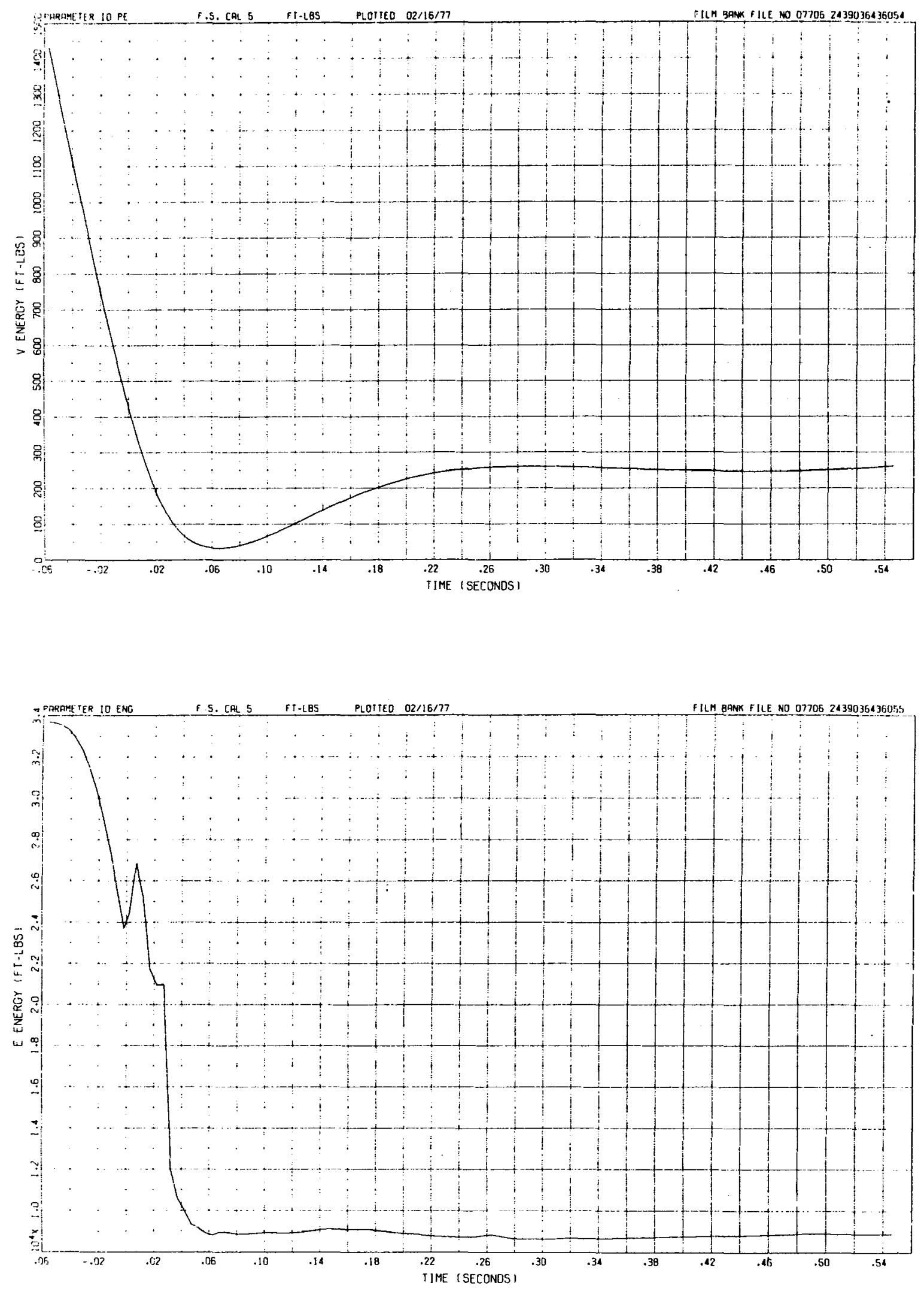

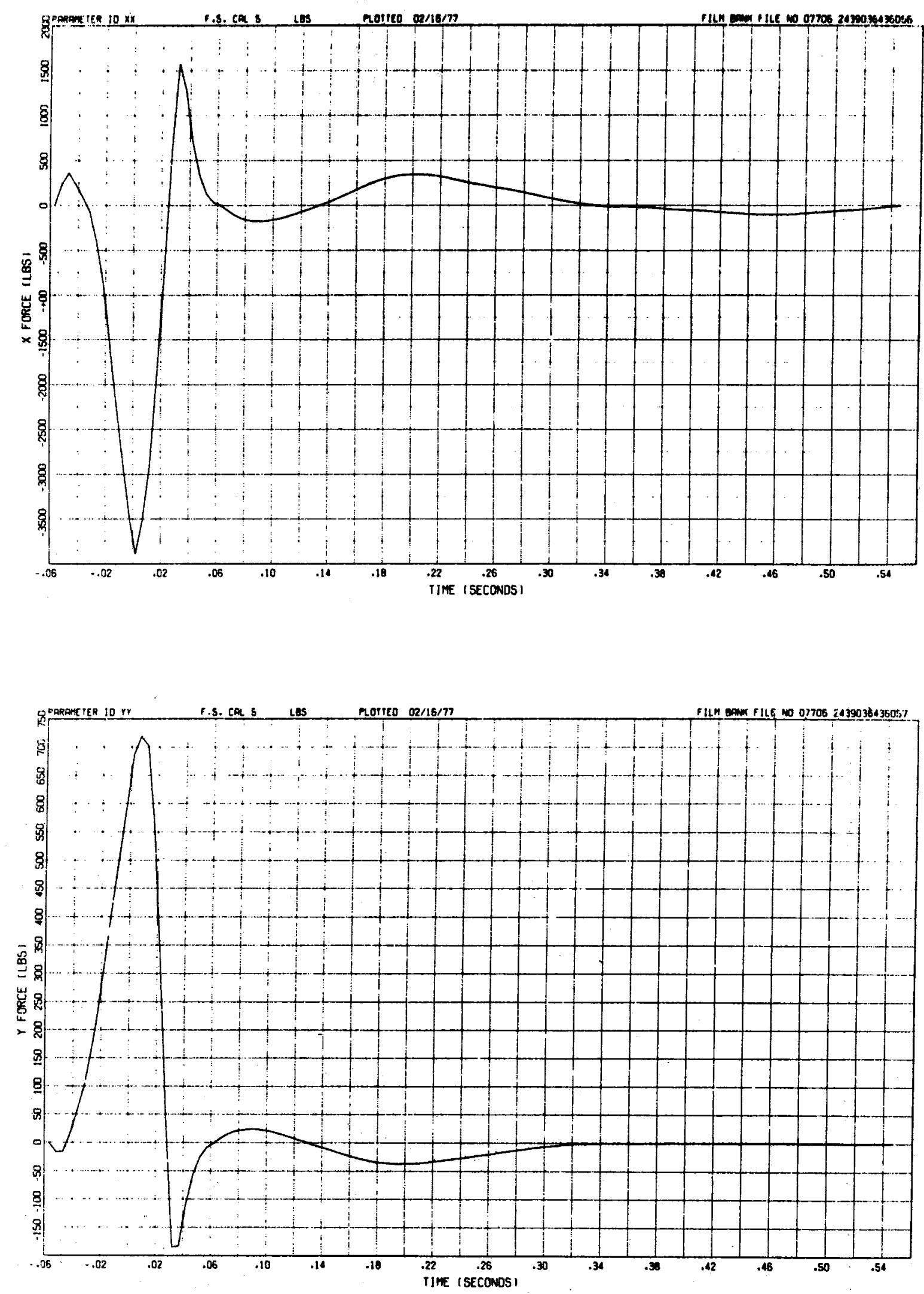

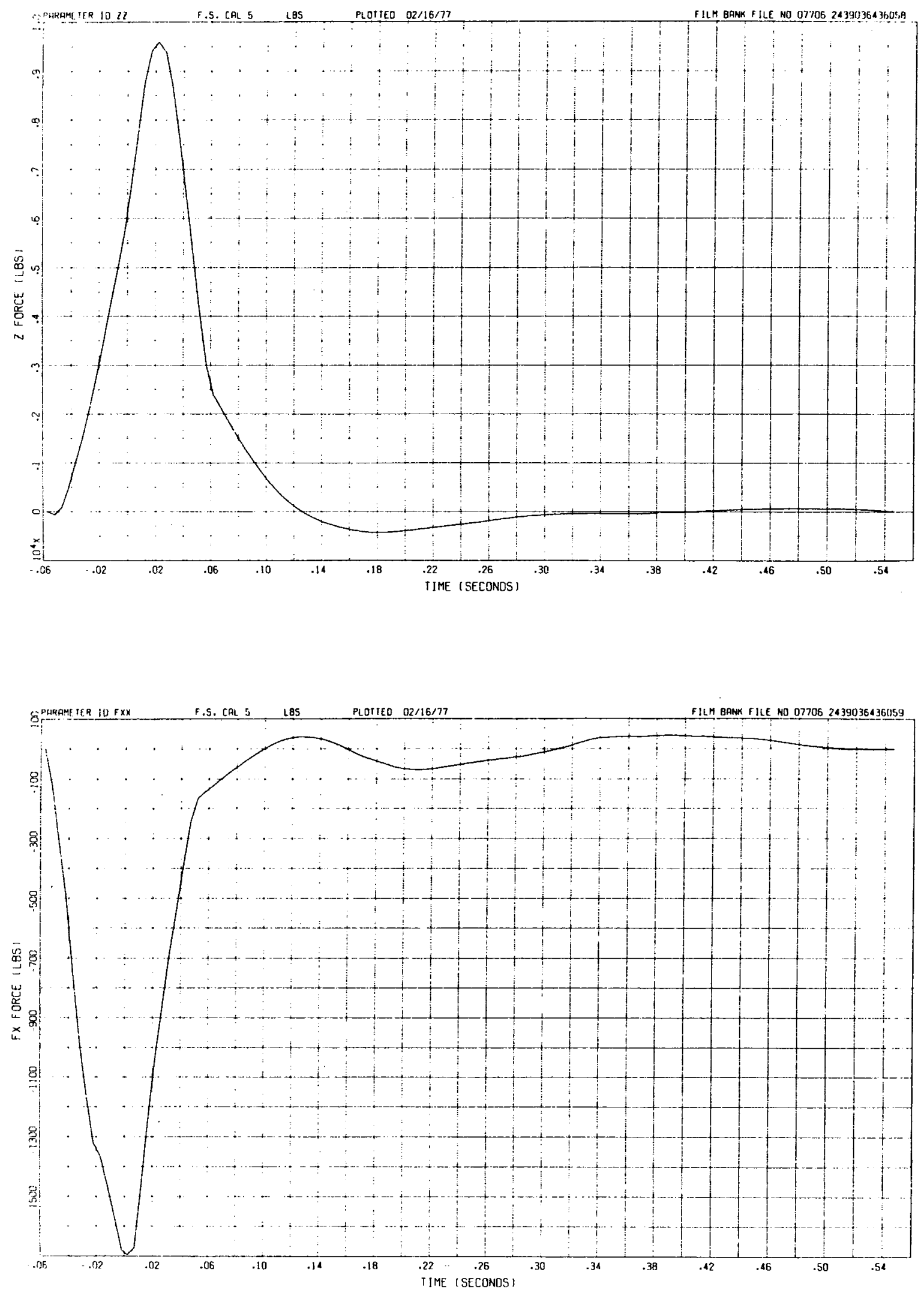

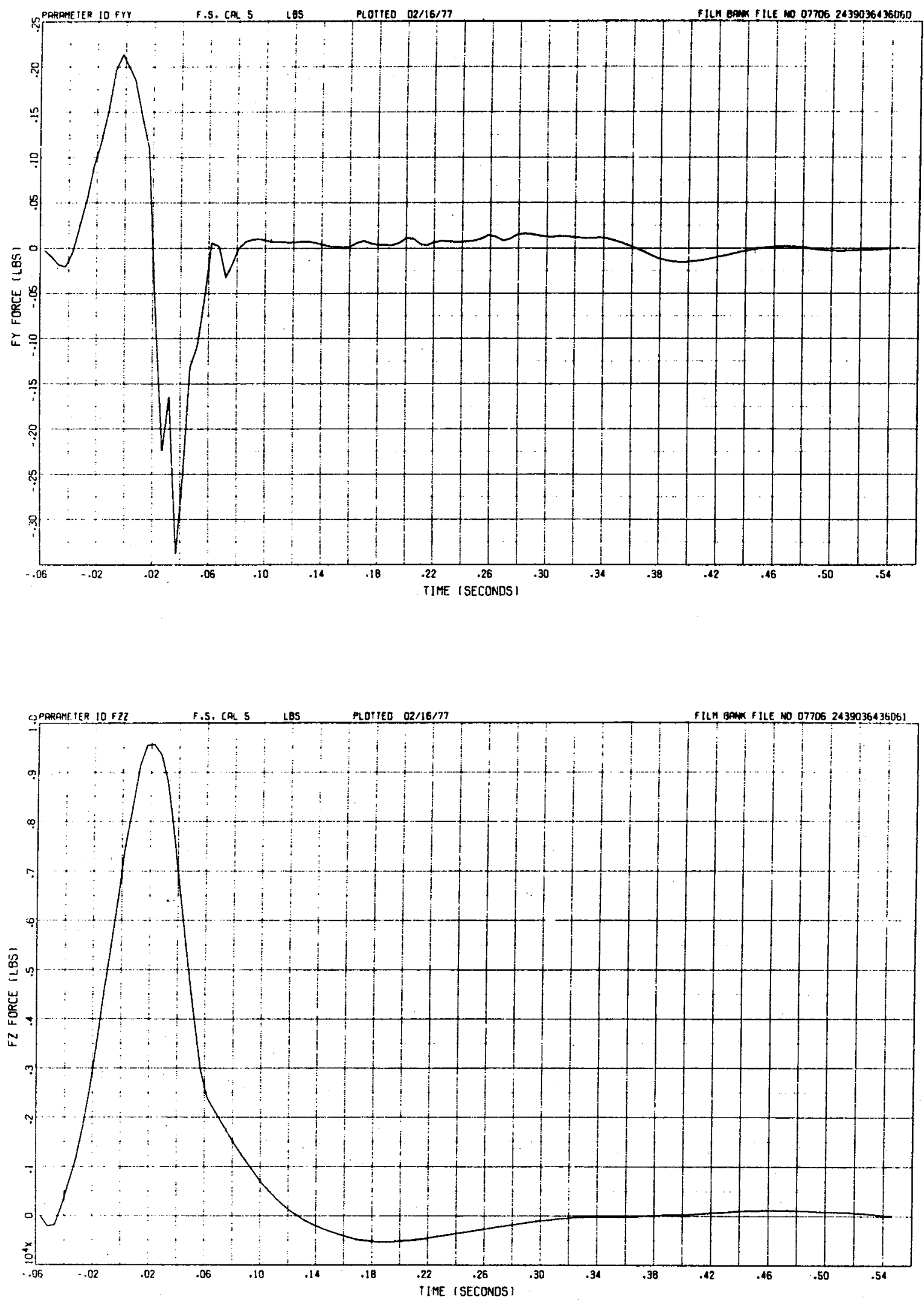

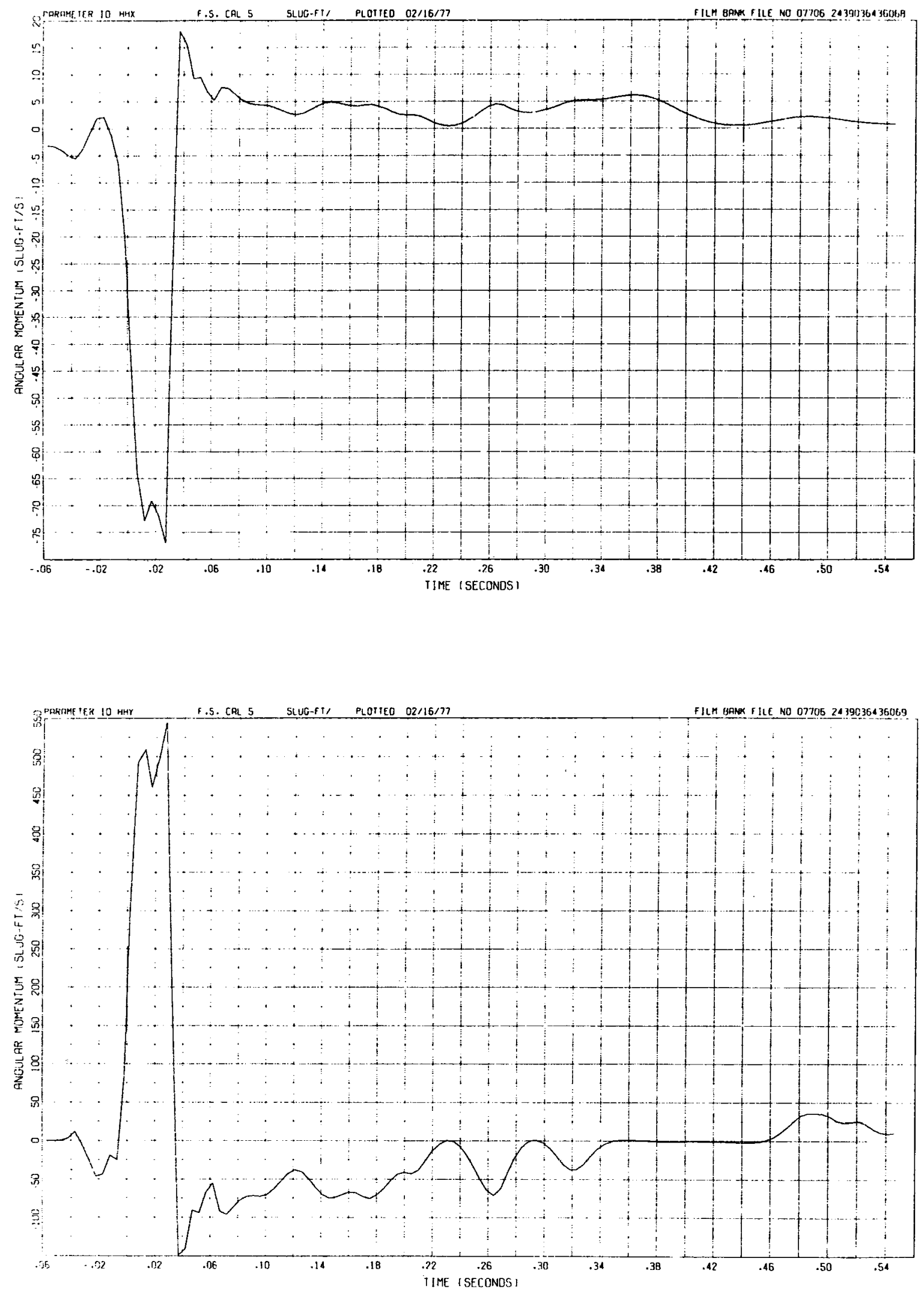

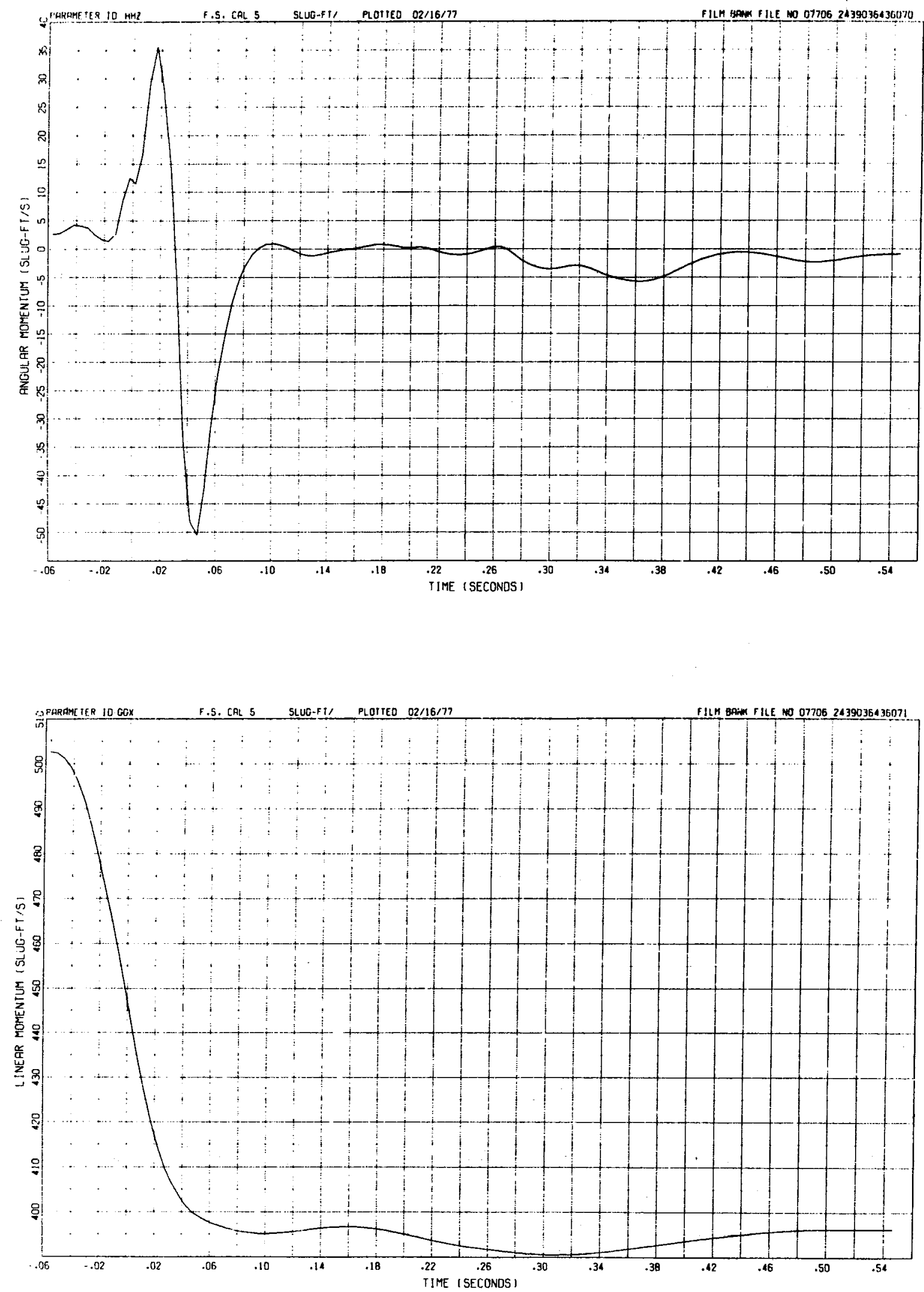

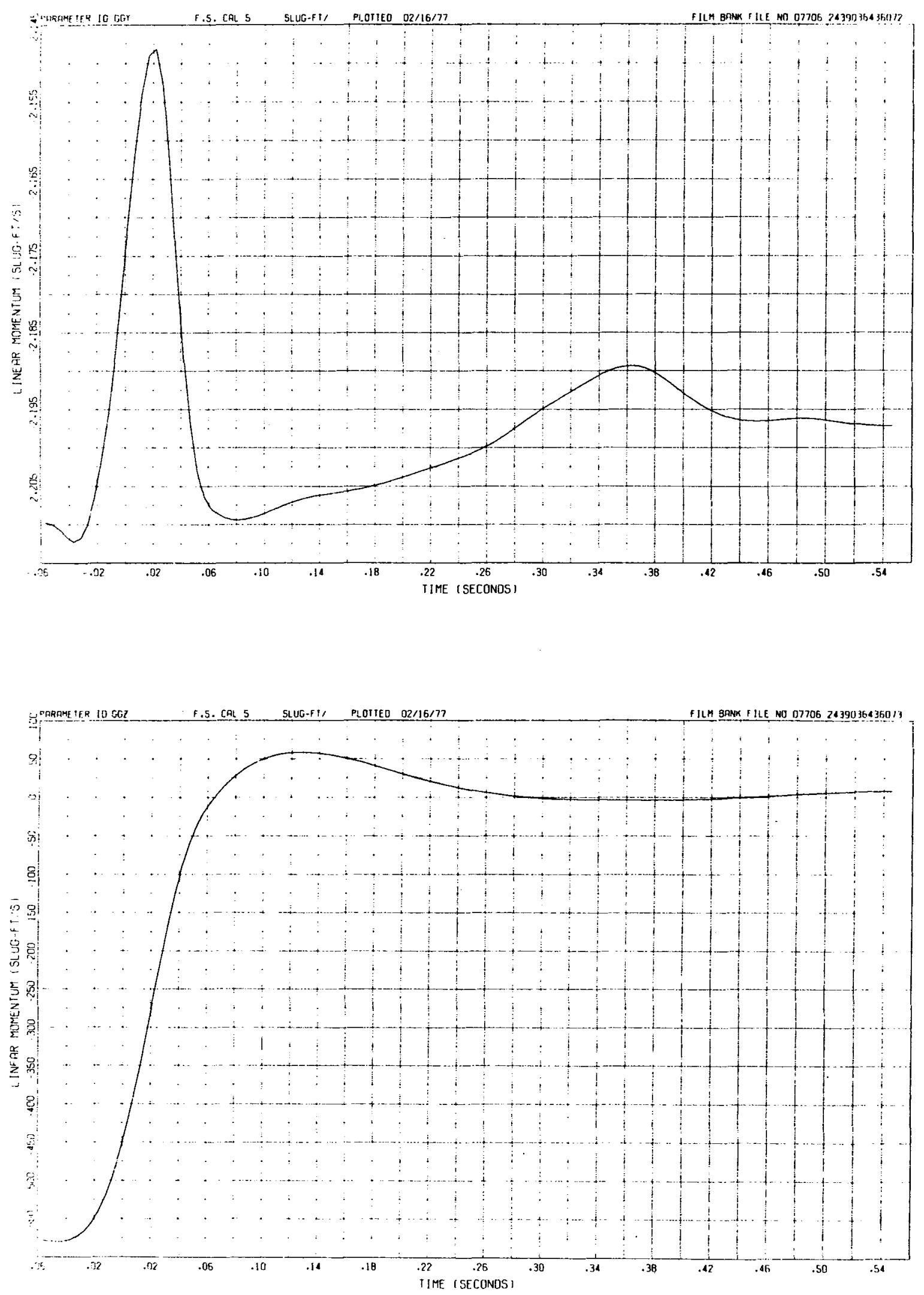


\section{UNL IMITED RELEASE}

\section{INITIAL DISTRIBUTION}

A. L. Harral, LLL, L 125

R. Clough, LLL, L 125

S. Sack, LLL, L24

T. B. Lane, 1280; Attn: T. G. Priddy, 1282

C. C. Burks, 4310

T. B. Cook, Jr., 8000; Attn: A. N. Blackwell, 8010

L. Gutierrez, 8100

C. H. DeSelm, 8200

W. E. Alzheimer, 8120

C. S. Hoyle, 8122

H. Hanser, 8141

D. E. Gregson, 8150

J. B. Wright, 8156; Attn: L. E. Dighton

G. N. Beeler, 8157

D. B. Starkey

J. C. Miller, 8157

W. R. Bolton, 8158

R. N. Everett, 8158

L. A. Hiles, 8158

R. E. Humphrey, 8158 (5)

A. S. Rivenes, 8158

R. E. Rychnovsky, 8158

R. D. Cozine, 8160

B. F. Murphey, 8300

T. S. Gold, 8320; Attn: R. E. Huddleston, 8325

R. Y. Lee, 8327

G. E. Strandin, 8321

J. D. Mansfield, 8325

J. F. Barham, 8360

W. C. Scrivner, 8400

R. A. Baroody, 8410; Attn: J. D. Benton, 8411

E. D. Holbrook, 8411 (5)

S. G. Cain, 8412; Attn: W. R. Guntrum

J. E. C. DeBaca, 9342

R. H. Schultz

J. L. Rogers, 9426

Technical Publications and Art Division, 8265, for TIC (2)

F. J. Cupps, 8265/Technical Library Processes Division, 3141

Technical Library Processes Division, 3141 (2)

Library and Security Classification Division, 8266-2 